\title{
S Research Square
PLAC8 Correlates with Prognosis, Immune Infiltration, and T Cell Exhaustion in Breast Cancer
}

\section{Pan Liao}

Inner Mongolia Forestry General Hospital

\section{Ying Wang}

Inner Mongolia University for Nationalities

\section{Lixia Sun ( $\nabla$ neimenggulinyezongyiyuan@bbkkbdg.cn )}

Inner Mongolia Forestry General Hosiptal https://orcid.org/0000-0002-4832-7964

Hongpeng Yue

Corqin District Center for Disease Control and Prevention

Primary research

Keywords: Immune infiltration, Immunotherapy, Breast cancer, Prognosis, T cells exhaustion, PLAC8.

Posted Date: August 24th, 2021

DOl: https://doi.org/10.21203/rs.3.rs-581866/v1

License: (c) (1) This work is licensed under a Creative Commons Attribution 4.0 International License. Read Full License 


\section{Abstract}

Background: Lysosomal protein placenta-specific 8 (PLAC8) with abundant cysteine, also referred to as onzin, participates in numerous cancers, and its effect is greatly determined by the cellular and tumor microenvironment (TME). Ourstudy focused on investigating the prognostic significance of PLAC8 and examined the association between PLAC8, immune infiltration, and T cells function in multiple malignancies comprehensively, particularly in breast cancer (BRCA).

Methods: PLAC8 expression in various malignancies was analyzed using TIMER. PrognoScan, KaplanMeier Plotter, and GEPIA2 were utilized to explore the significance of PLAC8 in prognostic prediction. Moreover, PLAC8 functions were systematically analyzed through cancerSEA. Additionally, TISIDB, TIMER, and GEPIA2 were also employed for analyzing the associations among PLAC8, immune infiltration, related gene marker sets, and clinical stages. Finally, PLAC8 and its co-expressed genes biological process and KEGG were analyzed.

Results: PLAC8 expression decreased in most malignancies and was related to poor prognosis in BRCA. PLAC8 significantly affected the survival of BRCA with ER status - array, PR status - IHC, HER2 status array, Intrinsic subtype, Grade, and Pietenpol subtype. Increased PLAC8 expression positively correlated with the increased immune infiltration levels within immune cells and many functional T cells (such as exhausted T cells). In BRCA cells, PLAC8 functional phenotypesshowed a negative correlation with invasion, metastasis, apoptosis, DNA damage, and DNA repair. Besides, PD-1, TIM-3, TIGIT, LAG3, and GZMB, critical genes of exhausted T cells, interacted with PLAC8. Further analysis indicated that PLAC8 was related to $T$ cell activation, proliferation and adhesion of leukocytes,adaptive immune response, cell adhesion molecules (CAMs), cytotoxicity-mediated by natural killer cells, and the NF-kappa B signal transduction pathway.

Conclusion:PLAC8 is a prognostic indicator in pan-cancers, especially BRCA. Elevated PLAC8 level could significantly enhance immune infiltration in CD4+ T cells, CD8+ T cells, and functional T cells. Additionally, PLAC8 was tightly associatedwith T cell exhaustion which possibly enhances the latterwithin BRCA. PLAC8 expression determination might help in prognosis, and modulation of PLAC8level within exhausted T cells, a novel approach for optimizing the therapeutic effect of immunotherapy on BRCA cases.

\section{Background}

Breast cancer (BRCA) is a frequently occurring cancer, ranking second among the causes of cancerassociated mortality among the female population [1, 2]. BRCA is mainly treated by surgery, radiotherapy, chemotherapy, and its efficacy has been substantially improved [3]. Recently, immunotherapy is adopted as a novel therapeutic approach due to the improved long-term survival and tolerable toxicity, and survival benefits for numerous patients with advanced malignancies. Therefore, immunotherapy might be the most promising therapeutic strategy for tumors [4]. However, BRCA's relatively high death rate may be 
ascribed to late diagnosis, dismal prognostic outcome, and high tumor recurrence and distant metastasis [5]. Immunotherapy is generally less efficient in BRCA patients due to a lack of appropriate biomarkers to select the optimal patients for the therapy [6]. Moreover, several studies have demonstrated that patient prognosis, as well as the chemotherapy and immunotherapy efficacy, are affected by tumor-infiltrating lymphocytes, including tumor-infiltrating neutrophils (TINs) and tumor-associated macrophages (TAMs) $[7,8]$. Thus, it is urgent to clarify the tumor-immune interaction immunophenotypes andidentify the novel immune-related therapeutic targets for BRCA.

Placenta-specific 8 (PLAC8, also referred to as onzin) is a protein containing 115 amino acids with abundant cysteine [9]. It was firstdiscovered to show high expression within the mouse placenta [10]. Thereafter, PLAC8 was found to modulate immunity, metabolism, and pathophysiological processes of cancer, like cell growth, apoptosis, differentiation, or autophagy [11-16]. PLAC8 affects cell proliferation through the regulation of phosphatidylinositol 3-kinases (PI3K)/protein kinase B(AKT) signal transduction pathway within the hepatocellular carcinoma (HCC). In addition, PLAC8 enhances radiotherapy resistance of nasopharyngeal carcinoma (NPC) via suppressing the PI3K/AKT/GSK3 $\beta$ pathway, whereas PLAC8 silencing sensitizes NPC cells to radiotherapy through the activation of the $\mathrm{PI} 3 K / A K T / G S K 3 \beta$ pathway. The above results suggested that PLAC8 plays a role as an oncogene or tumor suppressor geneduring cancer development. Nonetheless, it is still unclear about its possible function and underlying mechanisms in BRCApathogenic mechanism. Apoptosis has been reported as the primary mechanism responsible for programmed cell death, whereas cellular homeostasis and normal physiology are maintained via diverse mechanisms [17-19]. Apoptosis modulates different cell processes, such as cell growth, survival, and cell cycle [20,21]. As reported previously,apoptosis is induced by suppressing PI3K/AKT signal transduction pathway [22, 23].

In the current research, PLAC8 expression, its potential functions, and prognostic significance in diverse malignancies were comprehensively examined using numerous databases, including TIMER, PrognoScan, Kaplan-Meier (KM) plotter, GEPIA2, CancerSEA, TISIDB, MEXPRESS, and LinkedOmics. Moreover, TISIDB, TIMER, and GEPIA2 were employed to investigate the association of PLAC8 level with immune infiltration in pan-cancers. Consequently, PLAC8 is a possible prognostic biomarker for BRCA that sheds light on understanding the interactions among PLAC8 expression, tumor infiltration, and T cell exhaustion.

\section{Methods}

\subsection{TIMER Database Analysis}

TIMER, an easy-to-use online comprehensive resource, renders dynamic exploration and visualization of genomics and tumor immunologic information [24]. TIMER offers gene expression profiling data of 10897 TCGA-derived samples covering32 cancer types, employed to predictthe tumor-infiltrating immune cells (TIICs) abundances, including neutrophils, macrophages, dendritic cells (DCs), B cells, CD4 + T cells, and CD $8+T$ cells. For predicting six TIIC subsets abundance, constrained least-squares fitting was 
adopted to analyze selected gene expression, showing a negative correlation with tumor purity among all cancer types [25]. Herein, "Diff Exp module" and "Gene module" were used to detect PLAC8 expression in pan-cancers and investigate its association with six TIIC subset abundance. Wilcoxon test was adopted to determine the statistical significance of differential PLAC8 expression. In addition, the relationship of PLAC8 level with immune infiltration was also evaluated through the purity-adjusted partial Spearman correlation. Besides, tumor-infiltration degrees were compared among tumors with diverse somatic copy number alterations (SCNAs) of PLAC8 using the "SCNA module." "SCNA module" is defined by GISTIC 2.0, including high amplification (2), arm-level gain (1), diploid/normal (0), arm-level deletion ( 1 ), and deep deletion (-2). "Correlation module" was used to examine further PLAC8 expression relationship with TIIC gene markers, including B cells, neutrophils, effector Treg cells, T cells, central memory T cells, CD8 + $T$ cells, resident memory $T$ cells, effector $T$ cells, resting Treg cells, exhausted $T$ cells, natural killer cells (NK cells), effector memory T cells, Th1, macrophages, DCs and mast cells according to previous literature [26-29]. Functionally, this module could plot expression scatter plots between PLAC8 in specific cancer types, along with Spearman correlation and statistical significance. Additionally, we presented gene expression data in the form of log2 RSEM (RNA-Seq by Expectation-Maximization).

\subsection{PrognoScan Database Analysis}

As a freely accessible database, PrognoScan provides diverse cancer microarray datasets to assess the biological association of gene expression with the patient prognostic out come and the candidate diagnostic biomarkers or the related therapeutic targets [30]. In this study, PrognoScan was employed to investigate the relationship ofPLAC8level with cancer prognosis. Hazard ratios (HRs), related $95 \%$ confidence intervals (Cls), and COX P-values were determined. The PLAC8 prognostic prediction performance was also assessed.

\subsection{KM Plotter Database Analysis}

KM Plotter database, a web-based resource, efficiently exploits the prognostic significance of gene expression in 21 malignancies, including four large datasets, that is breast $(n=6234)$, lung $(n=3452)$, ovarian $(n=2190)$ as well as gastric $(n=1440)$ cancer [31]. We thus exploited the PLAC8 expression relationship to survival in these four types of cancer from KM Plotter, manifested by survival curves, logrank P-value, and $\mathrm{HR}(95 \% \mathrm{Cl})$.

\subsection{GEPIA2 Database Analysis}

GEPIA2 database is an online method to interactively analyze gene expression in tumor and normal tissue based on GTEx (Genotype-Tissue Expression) data and TCGA, characterized by offering tailored functions, such as differential expression, correlation, survival and dimensionality reduction analysis, profiling plotting, and similar gene detection [32]. The "survival analysis" function examined the correlation of PLAC8 expression with survival in pan-cancers in TCGA. Spearman correlation coefficient from the "correlation analysis" function was utilized to determine the PLAC8 relationship with tumorinfiltration immune cell gene markers.

\subsection{CancerSEA Database Analysis}


As the first database for single-cell sequencing (scRNA-seq), CancerSEA contributes to the comprehensive exploration of tumor cell functional states at the single-cell level. Typically,results of scRNA-seqcollected into the CancerSEA database are obtained from altogether 72 datasets at GEO, SRA, and Array Express websites. There are 41,900 cancer cell types originating from 25 cancers, while the results of functional analysis obtained based on datasets like HCMDB, StemMapper, and Cyclebase, and altogether 14 functional states were redefined [33]. As a result, this database was utilized to analyze the relationship between PLAC8 and BRCA.

\subsection{TISIDB Database Analysis}

TISIDB database is characterized by integrating high-throughput screening techniques with seven other retrieved public datasets. About 988 revealed immune-related anti-tumor genes, para-cancerous multiomics information, molecular profiles, and diverse resources for immunological data [34] to analyze the association between specific genes and chemokines, immunomodulators as well as lymphocytes. TISIDB database was adopted to determine PLAC8 expression relationship to BRCA's clinical stages and investigate the possible relationship of PLAC8 expression with immunomodulators and lymphocytes.

\subsection{MEXPRESS Database Analysis}

MEXPRESS was designed as an approach to visualizedata, including TCGA level, clinical information, DNA methylation status, and the relationships between them [35]. Here, MEXPRESS was used to investigate the PLAC8 gene methylation status and the associations of PLAC8 mRNA level with diverse clinical features among BRCA cases.

\subsection{LinkedOmics Database Analysis}

"LinkFinder" module of LinkedOmics, statistically analyzed PLAC8 co-expression by Pearson's test and was presented as volcano, heat, or scatter plots. "LinkInterpreter" module of LinkedOmics was adopted for GO (Biological Process) analysis and KEGG pathways through GSEA. The criteria included false discovery rate $(F D R)<0.05$, and simulations of 500 [36].

\subsection{Statistical analysis}

The KM Plotter, PrognoScan, TIMER, and GEPIA2 were employed to plot survival curves, whereas the logrank test was utilized to determine P-values, Cox P-values, and HRs. The two-sided Wilcoxon rank-sum test compared the infiltration degree of every SCNA category with normal tissue. Spearman's correlation assessed the association between PLAC8 level and other gene or immune infiltration levels in specific cancer types. $P \leq 0.05$ indicated statistical significance and is shown in the figures.

\section{Results}

\subsection{PLAC8 mRNA Expression in Various Human Malignancies}


PLAC8 mRNA levels were analyzed in cancerous and normal tissue covering various malignancies based on the TIMER database (Fig. 1). PLAC8 level was significantly downregulated in BRCA, CHOL, COAD, HNSC, KICH, LIHC, LUAD, LUSC, PRAD, READ, SKCM than normal tissues. Nevertheless, there was a significant upregulation in PLAC8 level in HNSC-HPVpos, KIRC, KIRP compared to the normal tissues.

\subsection{Prognostic Potential of PLAC8 in Cancers}

This study examined PLAC8 level association with patient prognosis comprehensively in three large cancer datasets to assess the prognostic significance of PLAC8.

PrognoScan evaluated the prognostic prediction performance ofPLAC8(Table S1). Consequently, the PLAC8 level was significantly related to survival inAML (Acute Myeloid Leukemia), skin cancer, and, particularly, breast cancer (Table 1).

Table 1

Significance of PLAC8 in predicting the prognosis of diverse cancers through PrognoScan

\begin{tabular}{|c|c|c|c|c|c|c|c|}
\hline DATASET & $\begin{array}{l}\text { CANCER } \\
\text { TYPE }\end{array}$ & SUBTYPE & ENDPOINT & $\mathbf{N}$ & $\begin{array}{l}\text { COX } \\
\text { PVALUE }\end{array}$ & $\ln (H R)$ & $\begin{array}{l}\text { HR } \\
{[95 \%} \\
\mathrm{Cl}^{\text {low }} \\
\left.\mathrm{Cl}^{\text {upp }}\right]\end{array}$ \\
\hline GSE5122 & $\begin{array}{l}\text { Blood } \\
\text { cancer }\end{array}$ & AML & Overall Survival & 58 & 0.020435 & 0.5 & $\begin{array}{l}1.65 \\
{[1.08-} \\
2.53]\end{array}$ \\
\hline GSE2034 & $\begin{array}{l}\text { Breast } \\
\text { cancer }\end{array}$ & & $\begin{array}{l}\text { Distant Metastasis } \\
\text { Free Survival }\end{array}$ & 286 & 0.030048 & -0.34 & $\begin{array}{l}0.71 \\
{[0.52-} \\
0.97]\end{array}$ \\
\hline $\begin{array}{l}\text { GSE1456- } \\
\text { GPL96 }\end{array}$ & $\begin{array}{l}\text { Breast } \\
\text { cancer }\end{array}$ & & Overall Survival & 159 & 0.020727 & -0.77 & $\begin{array}{l}0.46 \\
{[0.24-} \\
0.89]\end{array}$ \\
\hline GSE19234 & $\begin{array}{l}\text { Skin } \\
\text { cancer }\end{array}$ & Melanoma & Overall Survival & 38 & 0.043215 & -0.42 & $\begin{array}{l}0.66 \\
{[0.44-} \\
0.99]\end{array}$ \\
\hline
\end{tabular}

For further analysis, the relationship of PLAC8 level with prognosis in four large tumor datasets (BRCA, lung cancer, OV (Ovarian serous cystadenocarcinoma) and gastric cancer) was exploited based on the KM Plotter. Similarly, decreased PLAC8 level was related to poor prognosis in BRCA (OS: P = 0.00029, HR $=0.7[0.58-0.85]$ ), lung cancer (OS: $P=1.6 e-05, H R=0.76[0.67-0.86] ; P F S: P=0.01, H R=0.78$ [0.640.94]), OV (OS: $P=0.048, H R=0.88$ [0.77-1]; PFS: $P=0.034, H R=0.87$ [0.77-0.99]), and gastric cancer (PFS: $P=0.026, H R=0.8$ [0.65-0.97]) (Fig. 2A-H). According to the above findings, RNA-seq data of 33 malignancies derived from the TCGA portal were adopted to validate the prognostic prediction performance of PLAC8 using GEPIA2 (Fig. 2I, 2J). Poor overall survival (OS) $(P=0.0012, H R=0.58)$ and 
disease-free survival (DFS) $(P=0.014, \mathrm{HR}=0.62)(\mathrm{Fig} .2 \mathrm{~K}, 2 \mathrm{~L})$ in BRCA were related to decreased PLAC8 level. However, increased PLAC8 level predicted dismal OS $(P=2 e-08, H R=2.8)$ and DFS $(P=0.00056, H R$ $=1.7)(F i g .2 M, 2 N)$ in LGG. Similarly, in UVM (Uveal Melanoma), increased PLAC8 expression was also related to poor OS $(P=0.0042, \mathrm{HR}=4)$ and DFS $(P=0.0015, \mathrm{HR}=5.1)$ (Fig. 2O, 2P). Reduced PLAC8 expression was associated with poor OS in CESC $(P=0.046, H R=0.62)$ (Fig. 2Q) and SARC $(P=0.019$, $\mathrm{HR}=0.62)($ Fig. $2 \mathrm{R})$. Moreover, PLAC8 expression significantly affected OS in SKCM and DFS in CHOL, LIHC, LUSC, and THYM (Figure S1).

Considering the correlation of PLAC8 level with poor prognosis in BRCA patients, the KM Plotter database was employed to investigate the possible mechanisms to evaluate PLAC8 expression relationship to clinicopathological parameters. As a result, the PLAC8 level was significantly associated with OS, DFS, patient ER status - array, PR status - IHC, HER2 status - array, Intrinsic subtype, Grade, and Pietenpol subtype (Table 2). 
Table 2

Significance of PLAC8 in predicting the prognosis of diverse BRCA subtypes through KaplanMeier Plotter

\begin{tabular}{|c|c|c|c|c|}
\hline & os & & PFS & \\
\hline Subtypes & P-value & HR & P-value & HR \\
\hline \multicolumn{5}{|l|}{ ER status - IHC } \\
\hline ER positive & 0.091 & $0.76(0.56-1.05)$ & 0.052 & $0.86(0.74-1)$ \\
\hline ER negative & 0.0032 & $0.6(0.43-0.85)$ & 0.13 & $0.86(0.71-1.04)$ \\
\hline \multicolumn{5}{|l|}{ ER status - array } \\
\hline ER positive & 0.023 & $0.76(0.6-0.96)$ & 0.0036 & $0.84(0.74-0.94)$ \\
\hline ER negative & $3 e-04$ & $0.56(0.4-0.77)$ & $2.2 \mathrm{e}-05$ & $0.66(0.55-0.8)$ \\
\hline \multicolumn{5}{|l|}{ PR status - IHC } \\
\hline PR positive & 0.047 & $0.44(0.19-1.01)$ & 0.58 & $1.08(0.81-1.45)$ \\
\hline PR negative & 0.033 & $0.58(0.35-0.96)$ & 0.91 & $0.99(0.78-1.24)$ \\
\hline \multicolumn{5}{|l|}{ HER2 status - array } \\
\hline HER2 positive & 0.0036 & $0.58(0.4-0.84)$ & 0.00013 & $0.65(0.52-0.81)$ \\
\hline HER2 negative & 0.0016 & $0.7(0.56-0.87)$ & 0.0084 & $0.86(0.76-0.96)$ \\
\hline \multicolumn{5}{|l|}{ Intrinsic subtype } \\
\hline basal & $4 e-05$ & $0.44(0.3-0.66)$ & 0.00056 & $0.67(0.54-0.84)$ \\
\hline Luminal A & 0.16 & $0.8(0.58-1.09)$ & 0.0075 & $0.8(0.68-0.94)$ \\
\hline Luminal B & 0.0026 & $0.58(0.41-0.83)$ & 0.00035 & $0.72(0.61-0.86)$ \\
\hline HER2+ & 0.17 & $0.67(0.38-1.19)$ & 0.038 & $0.69(0.48-0.98)$ \\
\hline \multicolumn{5}{|l|}{ Lymph node status } \\
\hline Lymph node positive & 0.12 & $0.77(0.55-1.07)$ & 0.53 & $1.06(0.89-1.25)$ \\
\hline Lymph node negative & 0.27 & $0.82(0.58-1.16)$ & 0.076 & $0.86(0.74-1.02)$ \\
\hline \multicolumn{5}{|l|}{ Grade } \\
\hline 1 & 0.18 & $0.53(0.21-1.35)$ & 0.3 & $0.77(0.46-1.27)$ \\
\hline 2 & 0.096 & $0.71(0.47-1.06)$ & 0.18 & $0.86(0.69-1.07)$ \\
\hline 3 & 0.014 & $0.69(0.51-0.93)$ & 0.15 & $0.87(0.72-1.05)$ \\
\hline
\end{tabular}

Bold values indicate $P<0.05$. 


\begin{tabular}{|lllll|}
\hline \multicolumn{4}{|l}{ OS } & \multicolumn{3}{l|}{ PFS } \\
\hline TP53 status & & & & \\
\hline mutated & 0.32 & $0.72(0.37-1.4)$ & 0.3 & $0.78(0.48-1.25)$ \\
\hline wild type & 0.81 & $0.93(0.5-1.71)$ & 0.22 & $0.77(0.5-1.17)$ \\
\hline Pietenpol subtype & & & & \\
\hline basal-like 1 & 0.17 & $0.58(0.26-1.28)$ & 0.8 & $0.95(0.62-1.45)$ \\
\hline basal-like 2 & 0.54 & $0.74(0.27-1.98)$ & 0.56 & $1.2(0.65-2.2)$ \\
\hline Immunomodulatory & 0.84 & $1.08(0.49-2.38)$ & 0.026 & $1.69(1.06-2.68)$ \\
\hline mesenchymal & 0.035 & $0.49(0.25-0.97)$ & 0.66 & $0.91(0.62-1.36)$ \\
\hline mesenchymal stem-like & 0.027 & $0.29(0.09-0.93)$ & 0.47 & $0.77(0.38-1.56)$ \\
\hline Luminal androgen receptor & 0.038 & $0.53(0.29-0.97)$ & 0.0097 & $0.61(0.41-0.89)$ \\
\hline Bold values indicate P<0.05. & & & & \\
\hline
\end{tabular}

\subsection{PLAC8 function in a single BRCA cell}

Heterogeneity related to the diverse cancer cell functional phenotypes is the main obstacle hindering efficient anticancer treatment. Recently, achievements have been attained in single-cell sequencing (scRNA-seq) to understandcancer cell functional status at the cell level. As revealed by cancerSEA functional correlation analysis, PLAC8 functional phenotypes within BRCA cells showed a negative correlation with invasion, metastasis, apoptosis, DNA damage, and DNA repair (Fig. 3).

\subsection{Modulation of immune molecules by PLAC8}

TISIDB database was employed to analyze Spearman's correlation of PLAC8 expression with lymphocytes and immunomodulators. The classification of immunomodulators included major histocompatibility complex (MHC) molecules, immuno-inhibitors as well as immuno-stimulators. The resulting heatmap showed that in most malignancies, PLAC8 was significantly correlated with TILs and immunomodulators (MHC, immuno-inhibitors, immuno-stimulators) (Fig. 4). Therefore, PLAC8 could likely modulate these immune molecules.

\subsection{PLAC8 correlates with immune infiltration level in BRCA}

The survival and LNM(lymph node metastasis) in tumor patients can be predicted independently by TIL (tumor-infiltrating lymphocytes) frequency [37-39]. Thus, the TIMER database was utilized to examine the relationship of PLAC8expression with the degrees of immune infiltrationamong 39 types of 
malignancies (Figure S2). Consequently, the PLAC8 level was markedly associated with tumor purity among 31 cancers related tothe infiltration of B cells within 31 cancers. Moreover, the PLAC8 level was also related to CD8 + T cell, CD 4 + T cell, macrophage, neutrophil, and DC infiltration levels in 31, 31, 21, 29 , and 30 types of malignancies, respectively. PLAC8 level was not statistically associated with B cell, CD4 + T cell, neutrophil, DC, CD8 + T cell, and macrophage infiltration in mesothelioma (UVM) (Figure $S 2 A L)$. However, $P L A C 8$ level had a significant association with purity level $(R=-0.525, P=1.76 e-71), B$ cell $(R=0.42, P=5.76 e-43), C D 8+T$ cell $(R=0.442, P=5.87 e-48), C D 4+T$ cell $(R=0.56, P=1.60 e-80)$, neutrophil $(R=0.499, P=5.19 \mathrm{e}-61)$ and $D C(R=0.521, P=1.94 \mathrm{e}-67)$ in BRCA (Fig. 5A). KM plots based on the TIMER database were used to investigate the PLAC8 level relationship with immune cell infiltration in BRCA. Consequently, B cell infiltration was significantly related to BRCA prognosis $(P=0.046)$ (Fig. 5B). In addition, deletions or normal copy number of PLAC8 gene locus was related to elevated immune cell infiltration, except B cell, neutrophil, and DC. Although SCNA was not related to immune infiltration in B cell, neutrophil, and DC (Fig. 5C), our present findings indicated the essential effect of PLAC8 on immune infiltration degree, particularly DC, in BRCA.

\subsection{Relationship of PLAC8 with immune cell gene markers}

GEPIA2 and TIMER were utilized for correlation analysis between PLAC8 and TIIC gene makers in BRCA to exploit the correlation of PLAC8 with tumor immune infiltration.

The selection of gene markers of diverse functional T cells and common immune cell populations was consistent with the literature. The correlation analysis after tumor purity adjustment in BRCA is shown in Table 3. PLAC8 had a significant relationship with gene markers of B cells, monocytes, TAMs, T cells, CD8 + T cells, neutrophils, macrophages, DCs, NK cells, mast cells, and most functional T cells.

Intriguingly, the above findings demonstrated the robust association of PLAC8 with B cells, T cells, and functional T cells, consistent with previous studies, and revealed a correlation of PLAC8 with mast cells. 
Table 3

Association of PLAC8 with immune cell gene markers within BRCA using TIMER

\begin{tabular}{|c|c|c|c|c|c|}
\hline \multirow[b]{2}{*}{ Immune cell } & \multirow[b]{2}{*}{ Gene markers } & \multirow{2}{*}{$\begin{array}{l}\text { None } \\
\text { Cor }\end{array}$} & \multicolumn{3}{|c|}{ Purity } \\
\hline & & & P-value & Cor & P-value \\
\hline CD8 + T cell & CD8A & 0.746 & $\star \star \star$ & 0.749 & $\star \star \star$ \\
\hline . & CD8B & 0.729 & $\star \star \star *$ & 0.731 & $\star \star \star *$ \\
\hline \multirow[t]{7}{*}{ T cell } & CD6 & 0.758 & $\star \star \star *$ & 0.754 & $\star \star *$ \\
\hline & CD3D & 0.796 & $\star \star \star *$ & 0.793 & $\star \star \star *$ \\
\hline & CD3E & 0.797 & $\star \star \star *$ & 0.796 & $\star \star \star$ \\
\hline & SH2D1A & 0.782 & $\star \star \star \star ~$ & 0.778 & $\star \star \star$ \\
\hline & TRAT1 & 0.782 & $\star \star \star *$ & 0.779 & $\star \star \star *$ \\
\hline & CD3G & 0.755 & $\star \star \star *$ & 0.751 & $\star \star \star *$ \\
\hline & $\mathrm{CD} 2$ & 0.784 & $\star \star \star *$ & 0.781 & $\star \star \star *$ \\
\hline \multirow[t]{10}{*}{ B cell } & BLK & 0.725 & $\star \star \star *$ & 0.721 & $\star \star \star *$ \\
\hline & CD19 & 0.702 & $\star \star \star$ & 0.693 & $\star \star *$ \\
\hline & FCRL2 & 0.694 & $\star \star \star *$ & 0.689 & $\star \star \star *$ \\
\hline & MS4A1 & 0.775 & $\star \star *$ & 0.771 & $\star \star * *$ \\
\hline & KIAA0125 & 0.651 & $\star \star \star *$ & 0.641 & $\star \star \star *$ \\
\hline & TNFRSF17 & 0.647 & $\star \star \star *$ & 0.642 & $\star \star *$ \\
\hline & TCL1A & 0.795 & $\star \star \star *$ & 0.794 & $\star * *$ \\
\hline & SPIB & 0.802 & $\star \star \star *$ & 0.794 & $\star * *$ \\
\hline & PNOC & 0.564 & $\star \star \star *$ & 0.559 & $\star * *$ \\
\hline & CD79A & 0.705 & $\star * *$ & 0.697 & $\star * *$ \\
\hline \multirow[t]{2}{*}{ Monocyte } & CD86 & 0.553 & $\star * *$ & 0.547 & $\star * *$ \\
\hline & CD115(CSF1R) & 0.505 & $\star \star \star$ & 0.506 & $\star \star \star$ \\
\hline \multirow[t]{3}{*}{ TAM } & CCL2 & 0.524 & $\star \star \star$ & 0.525 & $\star \star \star$ \\
\hline & CD68 & 0.419 & $\star \star \star *$ & 0.413 & $\star \star \star *$ \\
\hline & IL10 & 0.493 & $\star \star \star$ & 0.484 & $\star \star \star *$ \\
\hline
\end{tabular}

Note: Purity, tumor purity-adjusted correlation. None, non-adjusted correlation. Cor, R-value obtained upon Spearman correlation. ${ }^{*} \mathrm{P}<0.01 ; * \star \mathrm{P}<0.001 ; * \star \star \mathrm{P}<0.0001$. 


\begin{tabular}{|c|c|c|c|c|c|}
\hline \multirow[b]{2}{*}{ M1 Macrophage } & \multirow[b]{2}{*}{ IRF5 } & \multirow{2}{*}{$\begin{array}{l}\text { None } \\
0.321\end{array}$} & \multicolumn{3}{|c|}{ Purity } \\
\hline & & & 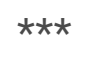 & 0.325 & 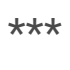 \\
\hline & COX2(PTGS2) & 0.405 & $\star \star \star$ & 0.402 & $\star \star \star$ \\
\hline \multirow[t]{3}{*}{ M2 Macrophage } & CD163 & 0.417 & 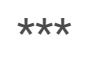 & 0.413 & $\star \star \star$ \\
\hline & VSIG4 & 0.269 & $\star \star \star$ & 0.277 & $\star \star \star$ \\
\hline & MS4A4A & 0.508 & $\star \star \star$ & 0.508 & $\star \star \star ~$ \\
\hline \multirow[t]{5}{*}{ Mast cell } & TPSB2 & 0.11 & $\star \star$ & 0.093 & * \\
\hline & TPSAB1 & 0.129 & $\star \star \star ~$ & 0.114 & $\star \star$ \\
\hline & СРАЗ & 0.119 & $\star \star \star *$ & 0.111 & $\star \star$ \\
\hline & MS4A2 & 0.126 & $\star \star \star ~$ & 0.116 & $\star \star$ \\
\hline & $\mathrm{HDC}$ & 0.18 & $\star \star \star$ & 0.167 & $\star \star \star$ \\
\hline \multirow[t]{8}{*}{ Neutrophils } & FPR1 & 0.431 & $\star \star \star ~$ & 0.433 & $\star \star \star$ \\
\hline & SIGLEC5 & 0.447 & $\star \star \star$ & 0.456 & $\star \star \star$ \\
\hline & CSF3R & 0.244 & $\star \star \star \star ~$ & 0.247 & $\star \star \star ~$ \\
\hline & FCAR & 0.327 & $\star \star \star ~$ & 0.327 & $\star \star \star$ \\
\hline & FCGR3B & 0.204 & $\star \star \star ~$ & 0.203 & $\star \star \star ~$ \\
\hline & CEACAM3 & 0.446 & $\star \star \star \star$ & 0.453 & 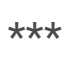 \\
\hline & S100A12 & 0.333 & $\star \star \star \star ~$ & 0.337 & $\star \star \star ~$ \\
\hline & CD116(ITGAM) & 0.351 & $\star \star \star \star$ & 0.351 & 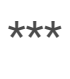 \\
\hline \multirow[t]{8}{*}{ Natural killer cell } & XCL1 & 0.669 & $\star \star \star \star$ & 0.676 & 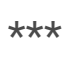 \\
\hline & XCL2 & 0.709 & $\star \star \star$ & 0.713 & $\star \star \star *$ \\
\hline & NCR1 & 0.523 & $\star \star \star *$ & 0.528 & $\star \star \star *$ \\
\hline & KIR2DL1 & 0.35 & $\star * \star$ & 0.354 & $\star \star \star *$ \\
\hline & KIR2DL3 & 0.419 & $\star \star \star *$ & 0.421 & $\star \star \star ~$ \\
\hline & KIR2DL4 & 0.532 & $\star \star \star$ & 0.525 & $\star \star \star$ \\
\hline & KIR3DL1 & 0.472 & $\star \star \star ~$ & 0.468 & $\star \star \star$ \\
\hline & KIR3DL2 & 0.543 & $\star \star \star \star$ & 0.552 & $\star \star \star ~$ \\
\hline
\end{tabular}

Note: Purity, tumor purity-adjusted correlation. None, non-adjusted correlation. Cor, R-value obtained upon Spearman correlation. ${ }^{*} \mathrm{P}<0.01 ;{ }^{* \star} \mathrm{P}<0.001 ;{ }^{* \star *} \mathrm{P}<0.0001$. 


\begin{tabular}{|c|c|c|c|c|c|}
\hline & \multirow[b]{2}{*}{ KIR3DL3 } & \multirow{2}{*}{$\begin{array}{l}\text { None } \\
0.269\end{array}$} & \multicolumn{3}{|c|}{ Purity } \\
\hline & & & $\star \star \star ~$ & 0.274 & $\star \star \star$ \\
\hline & KIR2DS4 & 0.369 & $\star \star \star *$ & 0.368 & $\star \star \star$ \\
\hline \multirow[t]{10}{*}{ Dendritic cell } & CCL13 & 0.576 & $\star \star \star *$ & 0.565 & $\star \star \star$ \\
\hline & CD209 & 0.476 & $\star \star \star$ & 0.473 & $\star \star \star$ \\
\hline & HSD11B1 & 0.615 & $\star * *$ & 0.609 & *** \\
\hline & HLA-DPB1 & 0.644 & $\star * \star$ & 0.64 & *** \\
\hline & HLA-DQB1 & 0.512 & $\star \star \star ~$ & 0.521 & $\star \star \star$ \\
\hline & HLA-DRA & 0.638 & $\star \star \star$ & 0.637 & $\star \star \star$ \\
\hline & HLA-DPA1 & 0.615 & $\star \star \star$ & 0.613 & $\star \star \star$ \\
\hline & BCDA-1(CD1C) & 0.717 & $\star \star \star ~$ & 0.715 & $\star \star \star$ \\
\hline & BDCA-4(NRP1) & 0.202 & $\star \star \star ~$ & 0.209 & $\star \star \star$ \\
\hline & CD11c(ITGAX) & 0.485 & $\star \star \star \star ~$ & 0.483 & $\star \star \star$ \\
\hline \multirow[t]{5}{*}{ Th1 } & T-bet(TBX21) & 0.763 & $\star \star \star *$ & 0.76 & $\star \star \star$ \\
\hline & IFN-y(IFNG) & 0.602 & $\star \star \star *$ & 0.601 & $\star \star \star$ \\
\hline & TNF-a(TNF) & 0.345 & 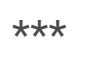 & 0.346 & $\star \star \star$ \\
\hline & STAT4 & 0.764 & $\star \star \star *$ & 0.759 & $\star \star \star$ \\
\hline & STAT1 & 0.429 & $\star \star \star \star$ & 0.43 & $\star \star \star$ \\
\hline \multirow[t]{4}{*}{ Th2 } & GATA3 & -0.306 & $\star \star \star \star ~$ & -0.307 & $\star \star \star$ \\
\hline & STAT6 & 0.115 & ** & 0.125 & *** \\
\hline & STAT5A & 0.369 & $\star * *$ & 0.364 & $\star \star *$ \\
\hline & IL13 & 0.272 & $\star \star \star$ & 0.263 & $\star \star \star$ \\
\hline \multirow[t]{2}{*}{ Tfh } & BCL6 & 0.111 & $\star \star$ & 0.115 & $\star \star$ \\
\hline & IL21 & 0.429 & $\star \star \star ~$ & 0.422 & $\star \star \star ~$ \\
\hline \multirow[t]{2}{*}{ Th17 } & STAT3 & 0.081 & * & 0.093 & * \\
\hline & IL17A & 0.24 & $\star \star \star \star$ & 0.242 & $\star \star \star$ \\
\hline Effector T cell & CX3CR1 & 0.168 & 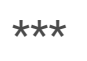 & 0.181 & *** \\
\hline
\end{tabular}

Note: Purity, tumor purity-adjusted correlation. None, non-adjusted correlation. Cor, R-value obtained upon Spearman correlation. ${ }^{*} \mathrm{P}<0.01 ;{ }^{* \star} \mathrm{P}<0.001 ;{ }^{* \star *} \mathrm{P}<0.0001$. 


\begin{tabular}{|c|c|c|c|c|c|}
\hline & \multirow[b]{2}{*}{ FGFBP2 } & \multirow{2}{*}{$\begin{array}{l}\text { None } \\
0.421\end{array}$} & \multicolumn{3}{|c|}{ Purity } \\
\hline & & & $\star \star \star ~$ & 0.416 & $\star \star \star$ \\
\hline & FCGR3A & 0.282 & $\star \star \star ~$ & 0.285 & $\star \star \star$ \\
\hline \multirow[t]{2}{*}{ Effector memory $\mathrm{T}$ cell } & GZMK & 0.766 & $\star * \star$ & 0.767 & $\star * \star$ \\
\hline & GZMA & 0.746 & $\star \star \star$ & 0.748 & $\star \star \star$ \\
\hline \multirow[t]{3}{*}{ Central memory T cell } & CCR7 & 0.816 & $\star \star \star *$ & 0.814 & $\star \star \star \star ~$ \\
\hline & SELL & 0.779 & 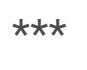 & 0.778 & 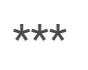 \\
\hline & IL7R & 0.684 & $\star \star \star ~$ & 0.676 & $\star \star \star$ \\
\hline \multirow[t]{3}{*}{ Resident memory $\mathrm{T}$ cell } & CD69 & 0.738 & $\star \star \star *$ & 0.729 & $\star \star \star *$ \\
\hline & ITGAE & 0.099 & ** & 0.094 & * \\
\hline & CXCR6 & 0.738 & $\star \star \star ~$ & 0.734 & $\star \star \star$ \\
\hline \multirow[t]{7}{*}{ Exhausted T cell } & PD-1 (PDCD1) & 0.717 & $\star \star \star \star ~$ & 0.711 & $\star \star \star ~$ \\
\hline & TIM-3 (HAVCR2) & 0.454 & $\star \star \star$ & 0.456 & $\star \star \star$ \\
\hline & TIGIT & 0.728 & $\star \star \star$ & 0.724 & $\star \star \star *$ \\
\hline & LAG3 & 0.544 & $\star \star \star \star ~$ & 0.532 & $\star \star \star ~$ \\
\hline & CXCL13 & 0.6 & $\star \star \star \star ~$ & 0.615 & $\star \star \star$ \\
\hline & LAYN & 0.197 & $\star \star \star *$ & 0.2 & $\star \star \star *$ \\
\hline & GZMB & 0.722 & $\star \star \star *$ & 0.713 & $\star \star \star *$ \\
\hline \multirow[t]{2}{*}{ Resting Treg T cell } & FOXP3 & 0.6 & $\star \star \star *$ & 0.593 & $\star \star *$ \\
\hline & IL2RA & 0.598 & $\star \star \star *$ & 0.584 & $\star \star \star \star ~$ \\
\hline \multirow[t]{3}{*}{ Effector Treg T cell } & CTLA4 & 0.681 & $\star \star \star *$ & 0.675 & $\star \star \star \star ~$ \\
\hline & CCR8 & 0.487 & $\star \star \star *$ & 0.482 & $\star \star \star *$ \\
\hline & TNFRSF9 & 0.6 & $\star \star \star *$ & 0.592 & $\star \star \star *$ \\
\hline
\end{tabular}

GEPIA2 was adopted to examine the association of the PLAC8 level with immune cell gene markers within non-carcinoma and BRCA specimens for validation (Table 4). Similarly, PLAC8 was positively associated with B cells, monocytes, TAMs, M1 macrophages, M2 macrophages, T cells, CD8 + T cells, neutrophils, DCs, NK cells, and various functional T cells, especially effector T cells, effector memory $T$ cells, central memory $T$ cells, resident memory $T$ cells, exhausted $T$ cells, resting Treg $T$ cells, effector Treg T cells, Th1 cells, and Th2 cells. In comparison, there was no significant association between 
PLAC8expression and immune cell gene markerswithin non-carcinoma specimens. Elevated PLAC8 level was related to enhanced DC infiltration in BRCA. DC markers, including HLA-DQB1, CCL13, HLA-DPA1, CD209, CD11C, HLA-DPB1, HLA-DRA, BDCA-1, and BDCA-4, were related to PLAC8 level, suggesting PLAC8 is tightly related to DC infiltration in the tumor. DCs aggravate tumor metastasis by inhibiting CD8 + T cell cytotoxicity and enhancing Treg responses [40]. In-depth research could confirm the vital role of PLAC8 in modulating tumor metastasis and DC infiltration. In our study, PLAC8 significantly interacted with various vital genes of exhausted T cell comprising PD-1 (Cor $=0.61, \mathrm{P}<.0001$ ), $\mathrm{TIM}-3$ (Cor $=0.3, \mathrm{P}<$ 0.0001), TIGIT (Cor = 0.75, P<.0001), LAG3 (Cor =0.38, P<0.0001), and GZMB (Cor $=0.53, P<0.0001)$, involved in cancer immunotherapy. 
Table 4

Association of PLAC8 with immune cell gene markers within BRCA detected usingGEPIA2

\begin{tabular}{|c|c|c|c|c|c|}
\hline & & Tumor & & Norma & \\
\hline Immune cell & Gene markers & Cor & P-value & Cor & P-value \\
\hline \multirow[t]{2}{*}{ CD8 + T cell } & CD8A & 0.62 & 0 & 0.51 & $6.6 \mathrm{e}-09$ \\
\hline & CD8B & 0.55 & 0 & 0.38 & $3.3 e-05$ \\
\hline \multirow[t]{7}{*}{$\mathrm{T}$ cell } & CD6 & 0.68 & 0 & 0.66 & $2.4 \mathrm{e}-15$ \\
\hline & CD3D & 0.72 & 0 & 0.68 & $2.2 \mathrm{e}-16$ \\
\hline & CD3E & 0.77 & 0 & 0.68 & $2.2 \mathrm{e}-16$ \\
\hline & SH2D1A & 0.73 & 0 & 0.66 & $1.6 \mathrm{e}-15$ \\
\hline & TRAT1 & 0.62 & 0 & 0.68 & $2.2 \mathrm{e}-16$ \\
\hline & CD3G & 0.66 & 0 & 0.57 & $5.4 \mathrm{e}-11$ \\
\hline & $\mathrm{CD} 2$ & 0.72 & 0 & 0.67 & $4.4 \mathrm{e}-16$ \\
\hline \multirow[t]{10}{*}{ B cell } & BLK & 0.63 & 0 & 0.63 & $5.8 e-14$ \\
\hline & CD19 & 0.64 & 0 & 0.63 & $1.3 e-13$ \\
\hline & FCRL2 & 0.62 & 0 & 0.65 & $1 e-14$ \\
\hline & MS4A1 & 0.62 & 0 & 0.63 & $9.4 e-14$ \\
\hline & KIAA0125 & 0.54 & 0 & 0.6 & $3 e-12$ \\
\hline & TNFRSF17 & 0.4 & 0 & 0.45 & $4.9 \mathrm{e}-07$ \\
\hline & TCL1A & 0.65 & 0 & 0.63 & $6.3 e-14$ \\
\hline & SPIB & 0.26 & 0 & 0.68 & $4.4 \mathrm{e}-16$ \\
\hline & PNOC & 0.52 & 0 & 0.64 & $4.2 \mathrm{e}-14$ \\
\hline & CD79A & 0.63 & 0 & 0.63 & $7.2 \mathrm{e}-14$ \\
\hline \multirow[t]{2}{*}{ Monocyte } & CD86 & 0.45 & 0 & 0.42 & $3.5 \mathrm{e}-06$ \\
\hline & CD115(CSF1R) & 0.33 & 0 & 0.18 & 0.064 \\
\hline \multirow[t]{3}{*}{ TAM } & CCL2 & 0.23 & $5.8 e-14$ & 0.057 & 0.55 \\
\hline & CD68 & 0.19 & $1.5 e-10$ & 0.16 & 0.095 \\
\hline & IL10 & 0.31 & 0 & 0.21 & 0.03 \\
\hline
\end{tabular}

Note: Tumor, single-gene marker correlation analysis within LUAD samples. Normal, correlation analysis in normal tissue of TCGA.Cor, R-value obtained upon Spearman's correlation. 


\begin{tabular}{|c|c|c|c|c|c|}
\hline \multirow[b]{2}{*}{ M1 Macrophage } & \multirow[b]{2}{*}{ IRF5 } & \multicolumn{2}{|l|}{ Tumor } & \multicolumn{2}{|c|}{ Normal } \\
\hline & & 0.27 & 0 & 0.59 & $9.8 \mathrm{e}-12$ \\
\hline & COX2(PTGS2) & 0.005 & 0.87 & 0.051 & 0.59 \\
\hline \multirow[t]{3}{*}{ M2 Macrophage } & CD163 & 0.22 & $4 e-13$ & 0.1 & 0.29 \\
\hline & VSIG4 & 0.14 & $5.3 e-06$ & 0.076 & 0.43 \\
\hline & MS4A4A & 0.31 & 0 & 0.068 & 0.48 \\
\hline \multirow[t]{5}{*}{ Mast cell } & TPSB2 & 0.0039 & 0.9 & 0.024 & 0.8 \\
\hline & TPSAB1 & 0.012 & 0.69 & 0.094 & 0.32 \\
\hline & СРАЗ & 0.034 & 0.27 & 0.13 & 0.19 \\
\hline & MS4A2 & 0.066 & 0.029 & 0.094 & 0.33 \\
\hline & $\mathrm{HDC}$ & -0.036 & 0.24 & 0.36 & 0.00011 \\
\hline \multirow[t]{8}{*}{ Neutrophils } & FPR1 & 0.22 & $7 e-14$ & 0.31 & 0.00075 \\
\hline & SIGLEC5 & 0.34 & 0 & 0.43 & $2.3 e-06$ \\
\hline & CSF3R & 0.013 & 0.67 & 0.17 & 0.067 \\
\hline & FCAR & 0.13 & $2.1 \mathrm{e}-05$ & 0.12 & 0.2 \\
\hline & FCGR3B & 0.012 & 0.69 & 0.073 & 0.44 \\
\hline & CEACAM3 & 0.13 & $8.3 e-06$ & 0.15 & 0.12 \\
\hline & S100A12 & 0.02 & 0.52 & 0.014 & 0.88 \\
\hline & CD116(ITGAM) & 0.096 & 0.0015 & 0.17 & 0.076 \\
\hline \multirow[t]{8}{*}{ Natural killer cell } & XCL1 & 0.51 & 0 & 0.38 & $3 e-05$ \\
\hline & XCL2 & 0.6 & 0 & 0.48 & 8.3e-08 \\
\hline & NCR1 & 0.62 & 0 & 0.22 & 0.021 \\
\hline & KIR2DL1 & 0.046 & 0.13 & 0.098 & 0.31 \\
\hline & KIR2DL3 & 0.52 & 0 & 0.14 & 0.13 \\
\hline & KIR2DL4 & 0.49 & 0 & 0.31 & 0.00093 \\
\hline & KIR3DL1 & 0.44 & 0 & 0.17 & 0.072 \\
\hline & KIR3DL2 & 0.33 & 0 & 0.4 & $1.4 \mathrm{e}-05$ \\
\hline
\end{tabular}

Note: Tumor, single-gene marker correlation analysis within LUAD samples. Normal, correlation analysis in normal tissue of TCGA.Cor, R-value obtained upon Spearman's correlation. 


\begin{tabular}{|c|c|c|c|c|c|}
\hline & & Tumor & & Normal & \\
\hline & KIR3DL3 & 0.011 & 0.72 & 0.23 & 0.014 \\
\hline & KIR2DS4 & 0.3 & 0 & 0.27 & 0.0034 \\
\hline \multirow[t]{10}{*}{ Dendritic cell } & CCL13 & 0.22 & $1.2 \mathrm{e}-13$ & 0.086 & 0.37 \\
\hline & CD209 & 0.31 & 0 & 0.044 & 0.65 \\
\hline & HSD11B1 & 0.042 & 0.17 & -0.079 & 0.41 \\
\hline & HLA-DPB1 & 0.49 & 0 & 0.5 & $1.4 \mathrm{e}-08$ \\
\hline & HLA-DQB1 & 0.38 & 0 & 0.21 & 0.028 \\
\hline & HLA-DRA & 0.49 & 0 & 0.64 & $2.2 \mathrm{e}-14$ \\
\hline & HLA-DPA1 & 0.47 & 0 & 0.58 & $3.1 \mathrm{e}-11$ \\
\hline & BCDA-1(CD1C) & 0.57 & 0 & 0.65 & $1.1 \mathrm{e}-14$ \\
\hline & BDCA-4(NRP1) & 0.11 & 0.00051 & -0.081 & 0.4 \\
\hline & CD11c(ITGAX) & 0.36 & 0 & 0.42 & $4.4 \mathrm{e}-06$ \\
\hline \multirow[t]{5}{*}{ Th1 } & T-bet(TBX21) & 0.67 & 0 & 0.58 & $1.7 e-11$ \\
\hline & IFN-Y(IFNG) & 0.35 & 0 & 0.48 & $6.2 \mathrm{e}-08$ \\
\hline & TNF-a(TNF) & 0.16 & $9.2 \mathrm{e}-08$ & 0.33 & 0.00041 \\
\hline & STAT4 & 0.74 & 0 & 0.41 & $9.2 \mathrm{e}-06$ \\
\hline & STAT1 & 0.29 & 0 & 0.34 & 0.00028 \\
\hline \multirow[t]{4}{*}{ Th2 } & GATA3 & -0.22 & $1.5 \mathrm{e}-13$ & 0.1 & 0.28 \\
\hline & STAT6 & 0.089 & 0.0034 & 0.2 & 0.037 \\
\hline & STAT5A & 0.23 & $7.1 \mathrm{e}-15$ & -0.22 & 0.018 \\
\hline & IL13 & 0.13 & $2.1 \mathrm{e}-05$ & -0.019 & 0.85 \\
\hline \multirow[t]{2}{*}{ Tfh } & BCL6 & 0.029 & 0.34 & -0.19 & 0.049 \\
\hline & IL21 & 0.52 & 0 & 0.65 & $9.8 \mathrm{e}-15$ \\
\hline \multirow[t]{2}{*}{ Th17 } & STAT3 & 0.0012 & 0.69 & 0.26 & 0.0054 \\
\hline & IL17A & 0.095 & 0.0018 & -0.076 & 0.42 \\
\hline Effector T cell & CX3CR1 & 0.098 & 0.0012 & 0.3 & 0.0014 \\
\hline
\end{tabular}

Note: Tumor, single-gene marker correlation analysis within LUAD samples. Normal, correlation analysis in normal tissue of TCGA.Cor, R-value obtained upon Spearman's correlation. 


\begin{tabular}{|c|c|c|c|c|c|}
\hline & \multirow[b]{2}{*}{ FGFBP2 } & \multicolumn{2}{|l|}{ Tumor } & \multicolumn{2}{|c|}{ Normal } \\
\hline & & 0.023 & 0.45 & -0.14 & 0.15 \\
\hline & FCGR3A & 0.15 & $1.6 \mathrm{e}-06$ & 0.33 & 0.00036 \\
\hline \multirow[t]{2}{*}{ Effector memory T cell } & GZMK & 0.69 & 0 & 0.69 & 0 \\
\hline & GZMA & 0.7 & 0 & 0.65 & $4.9 \mathrm{e}-15$ \\
\hline \multirow[t]{3}{*}{ Central memory $\mathrm{T}$ cell } & CCR7 & 0.36 & 0 & 0.7 & 0 \\
\hline & SELL & 0.23 & $7.5 e-15$ & 0.68 & $2.2 \mathrm{e}-16$ \\
\hline & IL7R & 0.66 & 0 & 0.54 & $9.4 \mathrm{e}-10$ \\
\hline \multirow[t]{3}{*}{ Resident memory $\mathrm{T}$ cell } & CD69 & 0.64 & 0 & 0.39 & $1.7 e-05$ \\
\hline & ITGAE & 0.052 & 0.087 & 0.051 & 0.59 \\
\hline & CXCR6 & 0.54 & 0 & 0.53 & $1.4 \mathrm{e}-09$ \\
\hline \multirow[t]{7}{*}{ Exhausted T cell } & PD-1 (PDCD1) & 0.61 & 0 & 0.69 & 0 \\
\hline & TIM-3 (HAVCR2) & 0.3 & 0 & 0.28 & 0.0025 \\
\hline & TIGIT & 0.75 & 0 & 0.71 & 0 \\
\hline & LAG3 & 0.38 & 0 & 0.54 & $5.9 \mathrm{e}-10$ \\
\hline & CXCL13 & 0.069 & 0.022 & 0.35 & 0.00014 \\
\hline & LAYN & 0.033 & 0.28 & 0.23 & 0.015 \\
\hline & GZMB & 0.53 & 0 & 0.65 & $1.3 e-14$ \\
\hline \multirow[t]{2}{*}{ Resting Treg T cell } & FOXP3 & 0.59 & 0 & 0.64 & $1.7 \mathrm{e}-14$ \\
\hline & IL2RA & 0.28 & 0 & 0.41 & $7.5 \mathrm{e}-06$ \\
\hline \multirow[t]{3}{*}{ Effector Treg T cell } & CTLA4 & 0.65 & 0 & 0.64 & $2 e-14$ \\
\hline & CCR8 & 0.3 & 0 & 0.67 & $4.4 \mathrm{e}-16$ \\
\hline & TNFRSF9 & 0.46 & 0 & 0.69 & 0 \\
\hline
\end{tabular}


Table 5

Summary of databases used in this study.

\begin{tabular}{|c|c|c|}
\hline Name & Link & Keywords \\
\hline TIMER & https://cistrome. shinyapps.io/timer/ & $\begin{array}{l}\text { tumor-infiltrating } \\
\text { immune cells; } \\
\text { gene expression; } \\
32 \text { cancer types }\end{array}$ \\
\hline PrognoScan & $\begin{array}{l}\text { http://dna00.bio.kyutech.ac.jp/Progn } \\
\text { oScan/ }\end{array}$ & prognosis \\
\hline Kaplan-Meier Plotter & http://kmplot.com/ & $\begin{array}{l}\text { survival curve; } \\
\text { subtype }\end{array}$ \\
\hline $\begin{array}{l}\text { GEPIA2 (Gene Expression Profiling } \\
\text { Interactive Analysis2) }\end{array}$ & http://gepia2.cancer-pku.cn/ & $\begin{array}{l}\text { gene expression; } \\
\text { survival curve; } \\
\text { isoform details; } \\
\text { genes correlation; } \\
\text { similar genes } \\
\text { detection }\end{array}$ \\
\hline CancerSEA & http://biocc.hrbmu.edu.cn/CancerSEA/ & $\begin{array}{l}\text { single-cell } \\
\text { sequencing; } \\
\text { functional states; } \\
25 \text { cancer types }\end{array}$ \\
\hline TISIDB & http://cis.hku.hk/TISIDB & $\begin{array}{l}30 \text { cancer types; } \\
\text { immunotherapy; } \\
\text { immune system }\end{array}$ \\
\hline MEXPRESS & https://mexpress.be/ & $\begin{array}{l}\text { Expression; DNA } \\
\text { methylation } \\
\text { status; } \\
\text { clinical data }\end{array}$ \\
\hline LinkedOmics & http://www.linkedomics.org & $\begin{array}{l}32 \text { cancer types; } \\
\text { expression; } \\
\text { target genes; } \\
\text { enrichment } \\
\text { analysis }\end{array}$ \\
\hline
\end{tabular}

\subsection{PLAC8 Expression in BRCA}

Four different types, C1 (wound healing type), C2 [interferon y (IFN-y) dominant type], C3 (inflammatory type), C4 (lymphocyte depleted type), and C6 (TGF-b dominant type), manifested the expression of PLAC8. PLAC8 was found highest and lowest in the C2 and C3 types, respectively (Fig. 6A). PLAC8 expression was further investigated in different molecular subtypes of BRCA using TISIDB. Five different 
molecular subtypes (basal, Her2, lumA, lumB, and normal) were identified in BRCA. PLAC8 expression was highest and lowest in the basal and lumB subtypes, respectively (Fig. 6B), indicating its potent relationship with the tumor immune microenvironment. However, the comparison of different BRCA stages $(I I V, X)$ was significantly based on the GEPIA2 database $(P=0.00436)$ (Fig. 6C). Furthermore, MEXPRESS analysis indicated that PLAC8 mRNA expression correlated with the BRCA estrogen receptor status, BRCA progesterone receptor status, histological type, menopause status, gender, tumor stage simplified, sample type, and subtype (Fig. 6D).

\subsection{PLAC8 co-expression networks in BRCA}

For an in-depth understanding of the biological significance of PLAC8 in BRCA, the co-expression pattern of PLAC8 was examined using the "LinkFinder" module in LinkedOmics (Fig. 7A). Heatmaps showed the top 50 genes showing positive and negativecorrelation with PLAC8 (Fig. 7B and 7C).

GSEA-based annotation of significant GO term demonstrated PLAC8 co-expressed genes participation in positive modulation of the adaptive immune response, $T$ cell activation, leukocyte cell-cell adhesion, leukocyte proliferation, cellular defense response as well as response to chemokine signaling pathway (Fig. 7D). KEGG analysis revealed primary gene enrichment in cytotoxicity mediated by natural killer cells, infection with Staphylococcus aureus, NF-kappa B signal transduction pathway, cell adhesion molecules (CAMs), chemokine signal transduction pathway, hematopoietic cell lineage, the interaction between cytokine and cytokine receptor (Fig. 7E).

\section{Discussion}

PLAC8 is a protein containing 115 amino acids with abundant cysteine [9], firstdiscovered to show high expression within mouse placenta [10]. According to our results, PLAC8 inhibits the apoptosis of BRCA through the activation of the PI3K/AKT/NF-KB signal transduction pathway. PLAC8 plays a vital role as an oncogene or tumor suppressor gene during cancer development [41]. Nevertheless, comprehensive study on the association between PLAC8 level and immune infiltration, T cell activity, andthe pan-cancer prognosis is limited. Our study revealed that PLAC8 level was associated withthe prognostic outcome of various malignancies, especially BRCA, by analyzing massive tumor specimens derived from a series of large public databases. Besides, PLAC8 expression was positively related to the degree of immune infiltration within BRCA. The analysis on gene expression correlations for $T$ cells robustly validated that PLAC8 significantly interactedwith numerous functional T cells within BRCA, particularly the exhausted T cells. Therefore, PLAC8 provides new directions as a possible prognostic biomarker for BRCA for exploiting the association of PLAC8 with T cell function and immune infiltration.

Our study comprehensively investigated PLAC8 expression and systematic prognostic signature in pancancers based on several public datasets in TIMER and 33 malignancies from TCGA-based GEPIA2, which revealed differential PLAC8 expression between cancerous and normal tissue in various malignancies. PLAC8 expression increased in HNSC-HPVpos, KIRC, and KIRP compared to normal tissue in the TIMER database. However, several datasets revealed lower PLAC8 expression in BRCA, CHOL, 
COAD, HNSC, KICH, LIHC, LUAD, LUSC, PRAD, READ, SKCM. The varied PLAC8 level in various malignancies in different databases might be due to variations in the data collection and intrinsic biological properties. However, a robust, consistent prognostic association of PLAC8 expression was found in these databases in BRCA. In PrognoScan, the PLAC8 level was significantly related to survival inAML, skin cancer, and, particularly, breast cancer. Further analysis using GEPIA2 and KM Plotter suggested that down-regulation of PLAC8 predicted the dismal prognostic outcome of BRCA, LUSC, OV, STAD, CESC, SARC, SKCM, CHOL, LIHC, and LUSC. Moreover, PLAC8 expression significantly correlated with patient ER status - array, PR status - IHC, HER2 status - array, Intrinsic subtype, Grade, and Pietenpol subtype. Collectively, these outcomes indicated PLAC8 as a prognostic biomarker for BRCA.

Similarly, CancerSEA analysis indicated the involvement of PLAC8 in cancer metastasis and invasion. Further, PLAC8 was verified to inhibit BRCA apoptosis by activatingPI3K/AKT/NF-KB signal transduction pathway. PLAC8 may play a role as an oncogene or a tumor suppressor gene during cancer development [41]. We, therefore, propose that PLAC8 could be a potential BRCA biomarker.

TISIDB-based assessment of the relationship of PLAC8 with the immune system revealed that it was significantly correlated with lymphocytes, immuno-inhibitors, immuno-stimulators, and MHC molecules. The T1-type chemokine epigenetic silencing was demonstrated as a new immune evasion mechanism within cancers, whereas epigenetic reprogramming facilitated theselective increase in the therapeutic efficacy in BRCA [42]. Therefore, PLAC8 associated with the above immune molecules might be a novel target to investigate immune evasion in BRCA, likely to function as an immunotherapeutic target. BRCA is classified into various molecular subtypes. TISIDB database analysis revealed that PLAC8 expression was the highest in basal subtype, followed by the normal type, Her2, lumA, and lumB types. Varied PLAC8 levels were detected in distinct immune subtypes in BRCA, with the highest in the C2 type. The in-depth and comprehensive study on PLAC8 gene expression in diverse databases of BRCA and subtypes indicated the potent correlation of PLAC8 with immunological properties in the tumor microenvironment (TME).

Due to the strong impact of PLAC8 on the immune system and the remarkable prognostic significance in BRCA, we analyzed the association between PLAC8 and the degree of immune infiltration within BRCA. Consequently, higher PLAC8expression predicted a markedly increased degree of immune infiltration within diverse immune cell subsets, such as CD8 + T and B cells, particularly neutrophils, CD4 + T cells, andDCs, with a higher correlation degree. Additionally, B cell infiltration was significantly related to BRCA prognosis. Despite the insignificant effect of varied SCNA of PLAC8 on immune infiltration degree of B cells, neutrophils, and DCs in BRCA, our focus was on the tight correlation of PLAC8 with immune cells. Analysis of PLAC8 and immune cell gene markers further demonstrated that PLAC8 closely interacted with most immune cells and diverse functional T cells, including central memory T cells, effector, and exhausted T cells. T cell exhaustion is a main obstacle for inadequate anti-tumor immunity [43-45]; hence it is essential to abolish the progression of exhausted T cells. In our study, increased PLAC8 level was positively correlated to various critical genes of exhausted T cells, including PD-1, TIM-3, TIGIT, LAG3, and GZMB, presently therapeutic targets or participate in immunotherapy $[46,47]$. 
Intriguingly, we revealed the dual roles of PLAC8. High PLAC8 level positively correlated with superior prognosis in various types of malignancies, including BRCA, and simultaneously triggered T cell exhaustion, leading to inadequate anti-tumor immunity. The underlying mechanism has been explained recently by several researchers. PLAC8 showeda positive effect on regulating the migration and invasion of trophoblasts by promoting Cdc42 and Rac1 activation [11]. Therefore, PLAC8 plays a diverse role in normal immunity development and modulating TME, which requires identification in a specific stage.

To summarize, the present outcomes implicated PLAC8 as a prognostic biomarker in pan-cancers, particularly BRCA. Elevated PLAC8 expression is associated with a high immune infiltration degree in B cells, CD4 + T cells, Macrophages, DCs, neutrophils, CD8 + T cells, and most functional T cells. Despite its vital function in immunity development, PLAC8 is significantly related to T cell exhaustion and might promote T cell exhaustion in BRCA. Therefore, PLAC8 expression determination might assist in prognostic prediction. Besides, its modulation within exhausted $T$ cells possibly could serve as the new approach for optimizingthe therapeutic effect of immunotherapy among BRCA cases.

\section{Declarations}

\section{Ethics approval and consent to participate}

Not applicable.

\section{Consent for publication}

Not applicable..

\section{Availability of data and materials}

Data supporting our findings are already included in the manuscript.

\section{Competing interests}

The authors declare that they have no competing interests.

\section{Funding}

Not applicable.

\section{Authors' contributions}

LP, WY and YHP conducted statistical analysis and drafted the manuscript. SLX conceived the research, participated in the research design and coordination, and provided suggestions on the writing of the manuscript. All authors read and approved the final manuscript.

\section{Acknowledgements}


Not applicable.

\section{References}

1. Ferlay J, Soerjomataram I, Dikshit R, Eser S, Mathers C, Rebelo M, et al. Cancer incidence and mortality worldwide: sources, methods and major patterns in GLOBOCAN 2012. Int J Cancer. 2015;136(5):E359-E86.

2. Siegel RL, Miller KD, Jemal A. Cancer statistics. 2018. CA Cancer J Clin. 2018;68(1):7-30; doi: 10.3322/caac. 21442.

3. Fan S, Yang Z, Ke Z, Huang K, Liu N, Fang X, et al. Downregulation of the long non-coding RNA TUG1 is associated with cell proliferation, migration, and invasion in breast cancer. Biomed Pharmacother. 2017;95:1636-43.

4. Bray F, Ferlay J, Soerjomataram I, Siegel RL, Torre LA, Jemal A. Global cancer statistics 2018 : GLOBOCAN estimates of incidence and mortality worldwide for 36 cancers in 185 countries. CA Cancer J Clin. 2018;68(6):394-424.

5. Helmy KY, Patel SA, Nahas GR, Rameshwar P. Cancer immunotherapy: accomplishments to date and future promise. Ther Deliv. 2013;4(10):1307-20.

6. Odunsi K. Immunotherapy in ovarian cancer. Ann Oncol. 2017;28(suppl_8):viii1-7. doi:10.1093/annonc/mdx444.

7. Zhang H, Liu H, Shen Z, Lin C, Wang X, Qin J, et al. Tumor-infiltrating neutrophils is prognostic and predictive for postoperative adjuvant chemotherapy benefit in patients with gastric cancer. Ann Surg. 2018;267(2):311-8.

8. Waniczek D, Lorenc Z, Śnietura M, Wesecki M, Kopec A, Muc-Wierzgoń M. Tumor-associated macrophages and regulatory $\mathrm{T}$ cells infiltration and the clinical outcome in colorectal cancer. Arch Immunol Ther Exp (Warsz). 2017;65(5):445-54.

9. Rissoan M-C, Duhen T, Bridon J-M, Bendriss-Vermare N, Péronne C, Vis BdS, et al. Subtractive hybridization reveals the expression of immunoglobulinlike transcript 7, Eph-B1, granzyme B, and 3 novel transcripts in human plasmacytoid dendritic cells. Blood. 2002;100(9):3295-303.

10. Galaviz-Hernandez C, Stagg C, De Ridder G, Tanaka TS, Ko MS, Schlessinger D, et al. Plac8 and Plac9, novel placental-enriched genes identified through microarray analysis. Gene. 2003;309(2):819.

11. Chang W-L, Liu Y-W, Dang Y-L, Jiang X-X, Xu H, Huang X, et al. PLAC8, a new marker for human interstitial extravillous trophoblast cells, promotes their invasion and migration. Development. 2018;145(2).

12. Kaistha BP, Lorenz H, Schmidt H, Sipos B, Pawlak M, Gierke B, et al. PLAC8 localizes to the inner plasma membrane of pancreatic cancer cells and regulates cell growth and disease progression through critical cell-cycle regulatory pathways. Cancer Res. 2016;76(1):96-107. 
13. Sasaki D, Kotoh J, Watadani R, Matsumoto K. New animal models reveal that coenzyme Q2 (Coq2) and placenta-specific 8 (Plac8) are candidate genes for the onset of type 2 diabetes associated with obesity in rats. Mamm Genome. 2015;26(11):619-29.

14. Li C, Ma H, Wang Y, Cao Z, Graves-Deal R, Powell AE, et al. Excess PLAC8 promotes an unconventional ERK2-dependent EMT in colon cancer. J CLIN INVEST. 2014;124(5):2172-87.

15. Kinsey C, Balakrishnan V, O’Dell MR, Huang JL, Newman L, Whitney-Miller CL, et al. Plac8 links oncogenic mutations to regulation of autophagy and is critical to pancreatic cancer progression. Cell Rep. 2014;7(4):1143-55.

16. Jimenez-Preitner M, Berney X, Uldry M, Vitali A, Cinti S, Ledford JG, et al. Plac8 is an inducer of $\mathrm{C} / \mathrm{EBP} \beta$ required for brown fat differentiation, thermoregulation, and control of body weight. Cell Metab. 2011;14(5):658-70.

17. Hidayat AFA, Chan CK, Mohamad J, Kadir HA. Leptospermum flavescens Sm. protect pancreatic $\beta$ cell function from streptozotocin involving apoptosis and autophagy signaling pathway in in vitro and in vivo case study. J Ethnopharmacol. 2018;226:120-31.

18. Karimian A, Ahmadi Y, Yousefi B. Multiple functions of p21 in cell cycle, apoptosis and transcriptional regulation after DNA damage. DNA Repair. 2016;42:63-71.

19. Nie F-q, Sun M, Yang J-s, Xie M, Xu T-p, Xia R, et al. Long noncoding RNA ANRIL promotes non-small cell lung cancer cell proliferation and inhibits apoptosis by silencing KLF2 and P21 expression. Mol Cancer Ther. 2015;14(1):268-77.

20. Du WW, Fang L, Yang W, Wu N, Awan FM, Yang Z, et al. Induction of tumor apoptosis through a circular RNA enhancing Foxo3 activity. Cell Death Differ. 2017;24(2):357-70.

21. Ichim G, Tait SW. A fate worse than death: apoptosis as an oncogenic process. Nat Rev Cancer. 2016;16(8):539.

22. Zhang H-W, Hu J-J, Fu R-Q, Liu X, Zhang Y-H, Li J, et al. Flavonoids inhibit cell proliferation and induce apoptosis and autophagy through downregulation of PI3Ky mediated $\mathrm{PI3K} / \mathrm{AKT} / \mathrm{mTOR} / \mathrm{p} 70 \mathrm{S6K} / \mathrm{ULK}$ signaling pathway in human breast cancer cells. Sci Rep. 2018;8(1):1-13.

23. Wang X-M, Yao M, Liu S-X, Hao J, Liu Q-J, Gao F. Interplay between the Notch and PI3K/Akt pathways in high glucose-induced podocyte apoptosis. Am J Physiol Renal Physiol. 2014;306(2):F205-F13.

24. Li T, Fan J, Wang B, Traugh N, Chen Q, Liu JS, et al. TIMER: a web server for comprehensive analysis of tumor-infiltrating immune cells. Cancer Res. 2017;77(21):e108-e10.

25. Mermel CH, Schumacher SE, Hill B, Meyerson ML, Beroukhim R, Getz G. GISTIC2. 0 facilitates sensitive and confident localization of the targets of focal somatic copy-number alteration in human cancers. Genome Biol. 2011;12(4):1-14.

26. Guo X, Zhang Y, Zheng L, Zheng C, Song J, Zhang Q, et al. Global characterization of T cells in nonsmall-cell lung cancer by single-cell sequencing. Nat Med. 2018;24(7):978-85.

27. Nirmal AJ, Regan T, Shih BB, Hume DA, Sims AH, Freeman TC. Immune cell gene signatures for profiling the microenvironment of solid tumors. Cancer Immunol Res. 2018;6(11):1388-400. 
28. Bhattacharya S, Dunn P, Thomas CG, Smith B, Schaefer H, Chen J, et al. ImmPort, toward repurposing of open access immunological assay data for translational and clinical research. Sci Data. 2018;5(1):1-9.

29. Danaher P, Warren S, Dennis L, D'Amico L, White A, Disis ML, et al. Gene expression markers of tumor infiltrating leukocytes. J Immunother Cancer. 2017;5(1):1-15.

30. Mizuno H, Kitada K, Nakai K, Sarai A. PrognoScan: a new database for meta-analysis of the prognostic value of genes. BMC Med Genomics. 2009;2(1):1-11.

31. Nagy Á, Lánczky A, Menyhárt O, Győrffy B. Validation of miRNA prognostic power in hepatocellular carcinoma using expression data of independent datasets. Sci Rep. 2018;8(1):1-9.

32. Tang Z, Kang B, Li C, Chen T, Zhang Z. GEPIA2: an enhanced web server for large-scale expression profiling and interactive analysis. Nucleic Acids Res. 2019;47(W1):W556-W60.

33. Yuan H, Yan M, Zhang G, Liu W, Deng C, Liao G, et al. CancerSEA: a cancer single-cell state atlas. Nucleic Acids Res. 2019;47(D1):D900-D8.

34. Ru B, Wong CN, Tong Y, Zhong JY, Zhong SSW, Wu WC, et al. TISIDB: an integrated repository portal for tumor-immune system interactions. Bioinformatics. 2019;35(20):4200-2.

35. Koch A, De Meyer T, Jeschke J, Van Criekinge W. MEXPRESS: visualizing expression, DNA methylation and clinical TCGA data. BMC Genom. 2015;16(1):1-6.

36. Vasaikar SV, Straub P, Wang J, Zhang B. LinkedOmics: analyzing multi-omics data within and across 32 cancer types. Nucleic Acids Res. 2018;46(D1):D956-D63.

37. Ohtani H. Focus on TILs: prognostic significance of tumor infiltrating lymphocytes in human colorectal cancer. Cancer Immunity Archive. 2007;7(1).

38. Ravelli A, Roviello G, Cretella D, Cavazzoni A, Biondi A, Cappelletti MR, et al. Tumor-infiltrating lymphocytes and breast cancer: beyond the prognostic and predictive utility. Tumor Biol. 2017;39(4):1010428317695023.

39. Azimi F, Scolyer RA, Rumcheva P, Moncrieff M, Murali R, McCarthy SW, et al. Tumor-infiltrating lymphocyte grade is an independent predictor of sentinel lymph node status and survival in patients with cutaneous melanoma. J Clin Oncol. 2012;30(21):2678-83.

40. Sawant A, Hensel JA, Chanda D, Harris BA, Siegal GP, Maheshwari A, et al. Depletion of plasmacytoid dendritic cells inhibits tumor growth and prevents bone metastasis of breast cancer cells. J Immunol. 2012;189(9):4258-65.

41. Mao M, Chen Y, Jia Y, Yang J, Wei Q, Li Z, et al. PLCA8 suppresses breast cancer apoptosis by activating the PI3K/AKT/NF-KB pathway. J Cell Mol Med. 2019;23(10):6930-41.

42. Peng D, Kryczek I, Nagarsheth N, Zhao L, Wei S, Wang W, et al. Epigenetic silencing of TH 1-type chemokines shapes tumour immunity and immunotherapy. Nature. 2015;527(7577):249-53.

43. Zarour HM. Reversing T-cell dysfunction and exhaustion in cancer. Clin Cancer Res. 2016;22(8):1856-64. 
44. Wherry EJ, Kurachi M. Molecular and cellular insights into T cell exhaustion. Nat Rev Immunol. 2015;15(8):486-99.

45. Wherry EJ. T cell exhaustion. Nat Immunol. 2011;12(6):492-9.

46. Anderson AC, Joller N, Kuchroo VK. Lag-3. Tim-3, and TIGIT: co-inhibitory receptors with specialized functions in immune regulation. Immunity. 2016;44(5):989-1004.

47. Ribas A, Wolchok JD. Cancer immunotherapy using checkpoint blockade. Science. 2018;359(6382):1350-5.

\section{Figures}

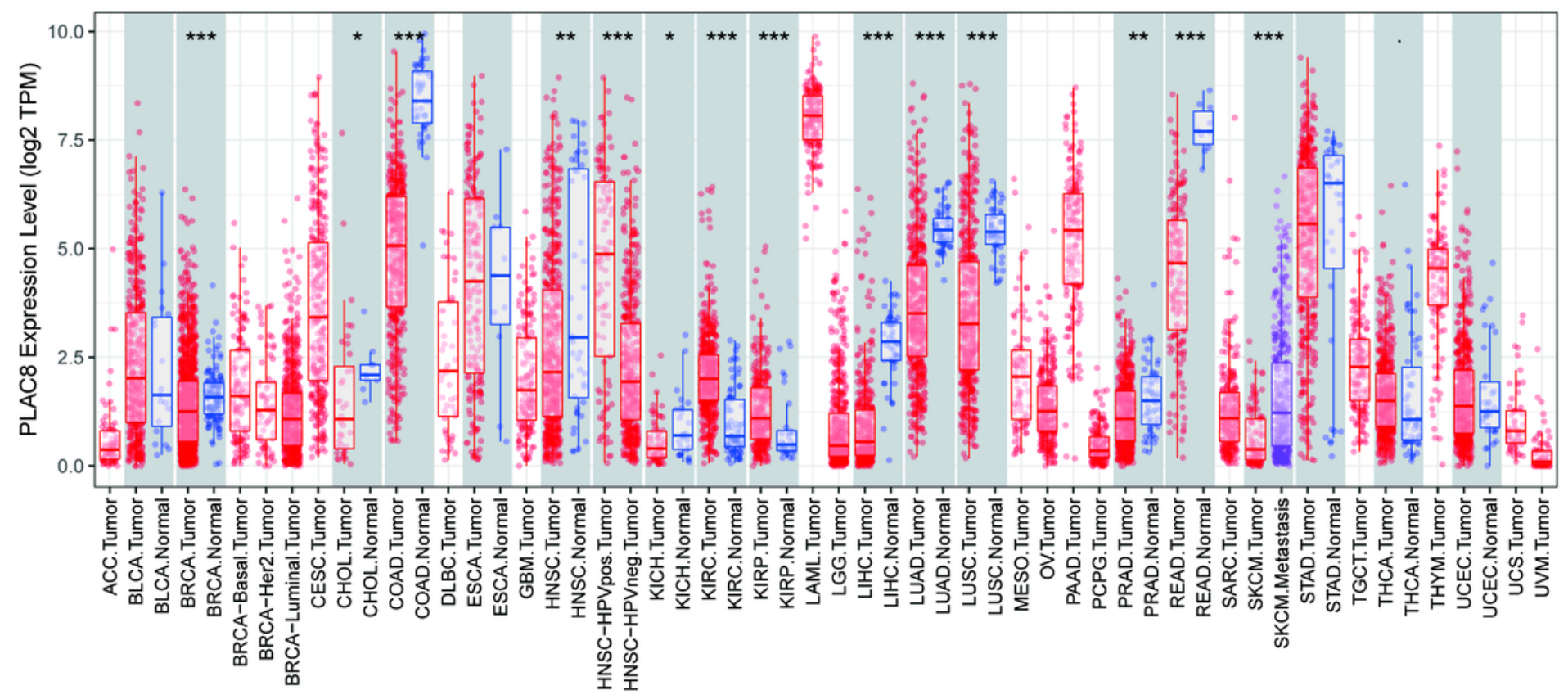

Figure 1

TIMER was employed to examine human PLAC8 expression in various cancers based on the TCGA database. $0 \leq * \star *<0.001 \leq * *<0.01 \leq *<0.05$ 

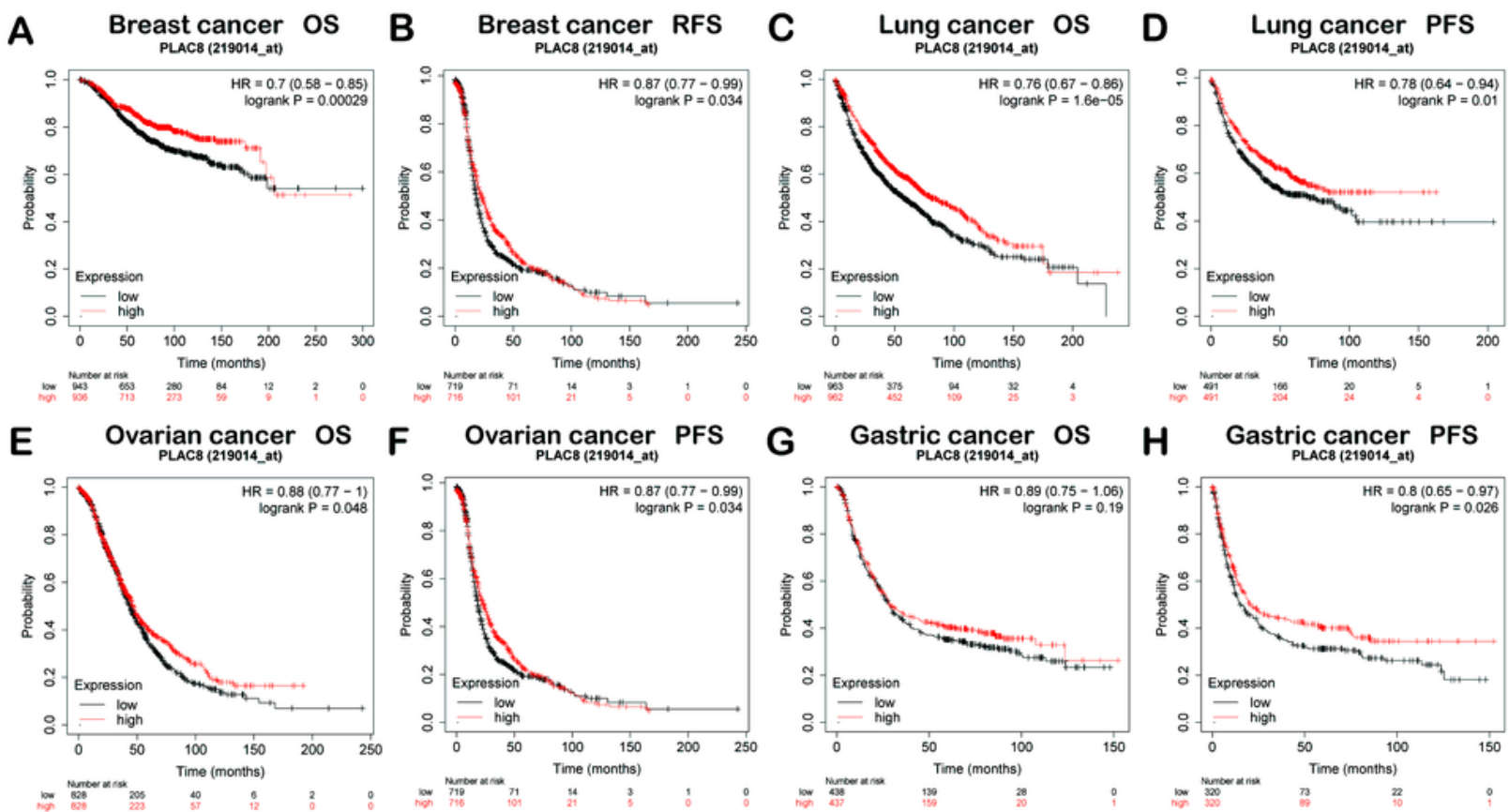

\section{I}

ENSG00000145287.10

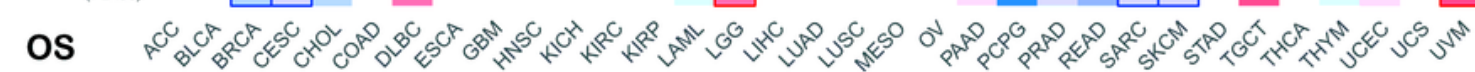
$\boldsymbol{J}_{\text {ENSG00000 } 14528710}$

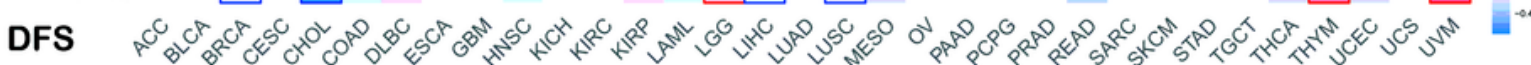
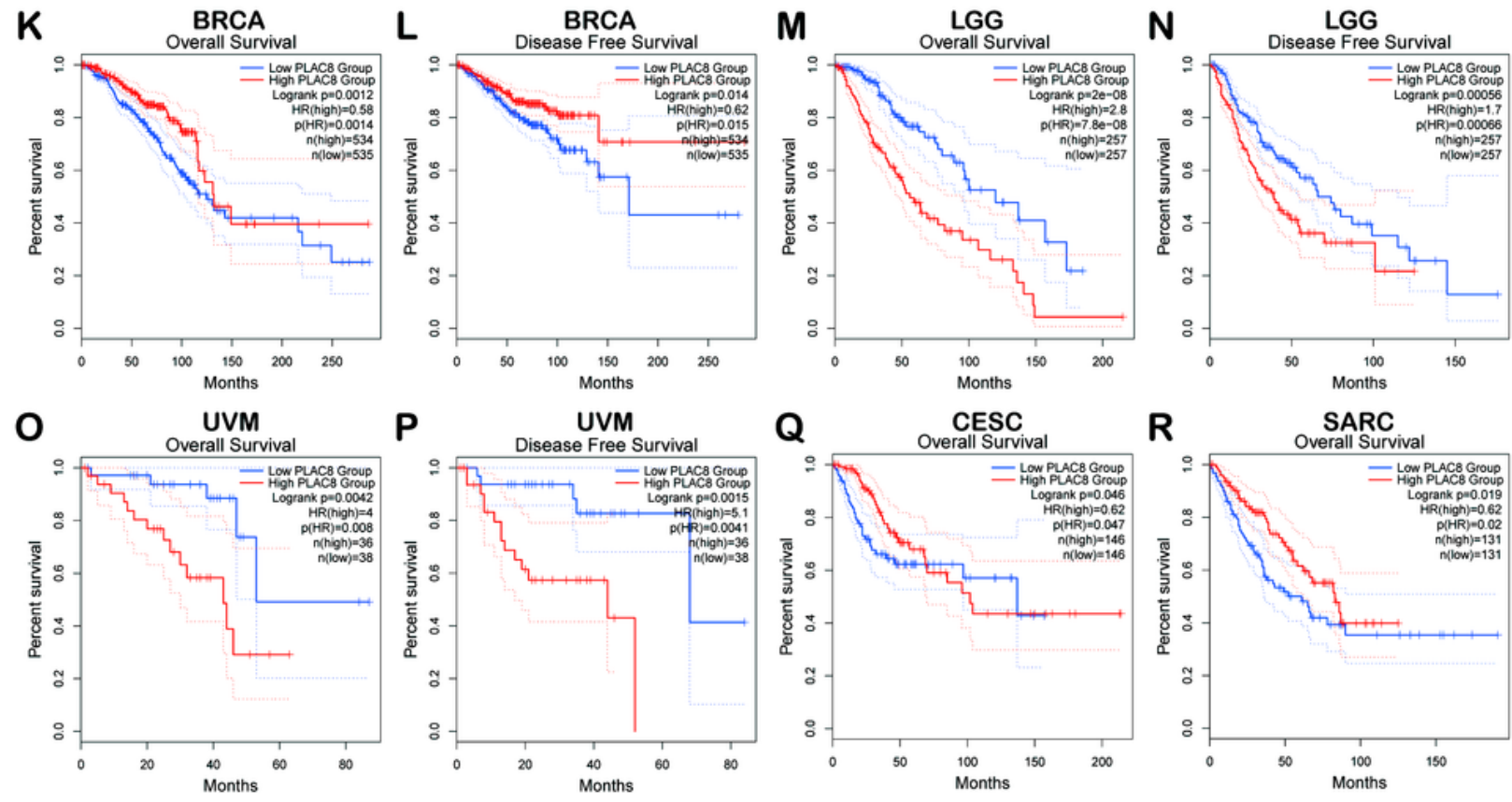

Figure 2

Prognostic possibility of PLAC8 in various tumors based on KM Plotter (A-H) and GEPIA2 (I-R). OS and RFS survival curves in $(A, B)$ breast cancer $(n=1879, n=1435)$. OS and PFS curves in $(C, D)$ lung cancer $(n=1925, n=982),(E, F)$ ovarian cancer $(n=1656, n=1435)$, and $(G, H)$ gastric cancer $(n=875, n=$ 640). $(\mathrm{I}, \mathrm{J})$ Heat map of PLAC8 in 33 types of TCGA tumors. Heat map revealed the HRs in logarithmic scale (log10) for PLAC8. The blue and red blocks suggested lower and higher risks, respectively. 
Rectangles with frames indicate statistically significant findings in the prognostic analysis. OS as well as DFS curves in $(K, L)$ BRCA $(n=1069),(M, N)$ LGG $(n=514)$, and $(O, P)$ UVM $(n=74)$. OS curves in(Q) CESC $(n=292),(R)$ SARC $(n=262)$.
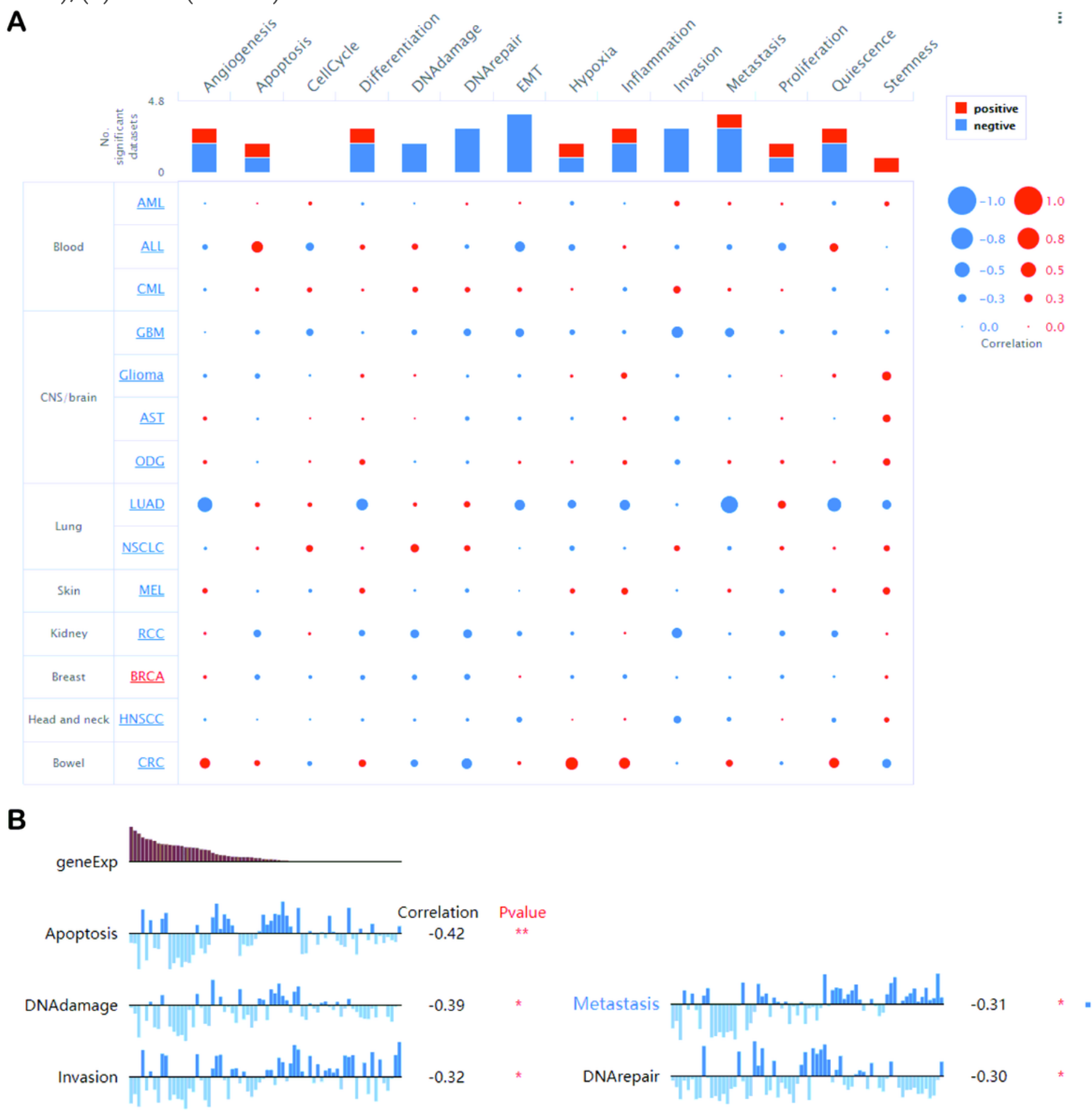

\section{Figure 3}

Functional analysis of PLAC8 in BRCA using CancerSEA database (A) Functional significance of PLAC8 within BRCA cells. Bubble size stands for correlation strength; blue and red colors indicate negative and positive correlations, respectively. (B) Detailed functional significance of PLAC8 within BRCA. ${ }^{*}<=0.05$, $\star \star P<=0.01, * \star * P<=0.001$ 
A

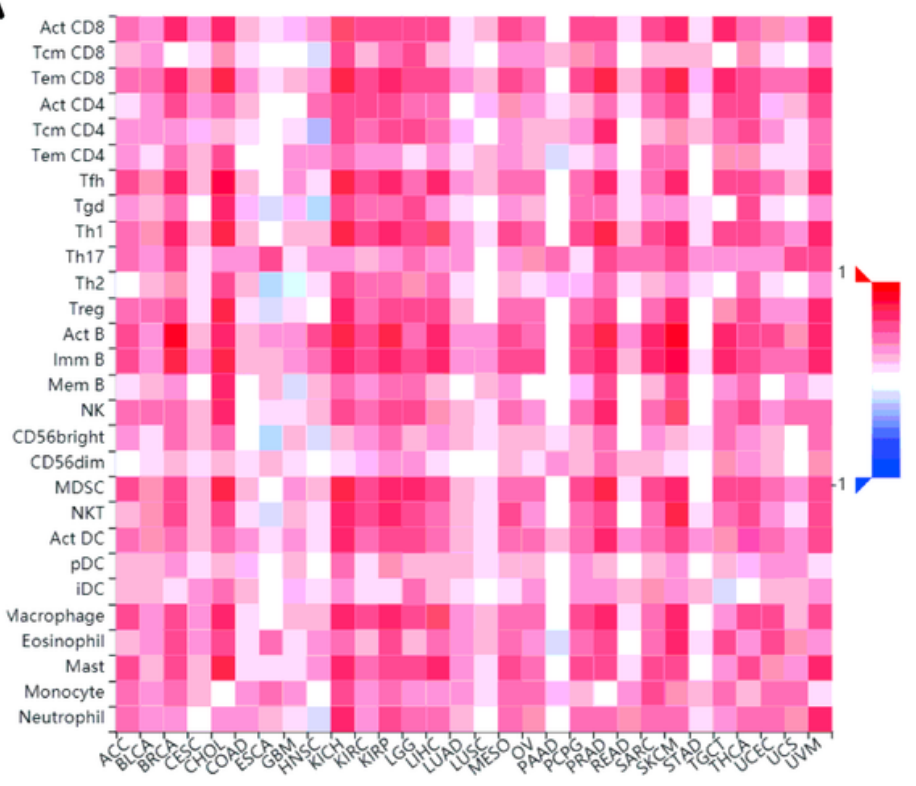

C

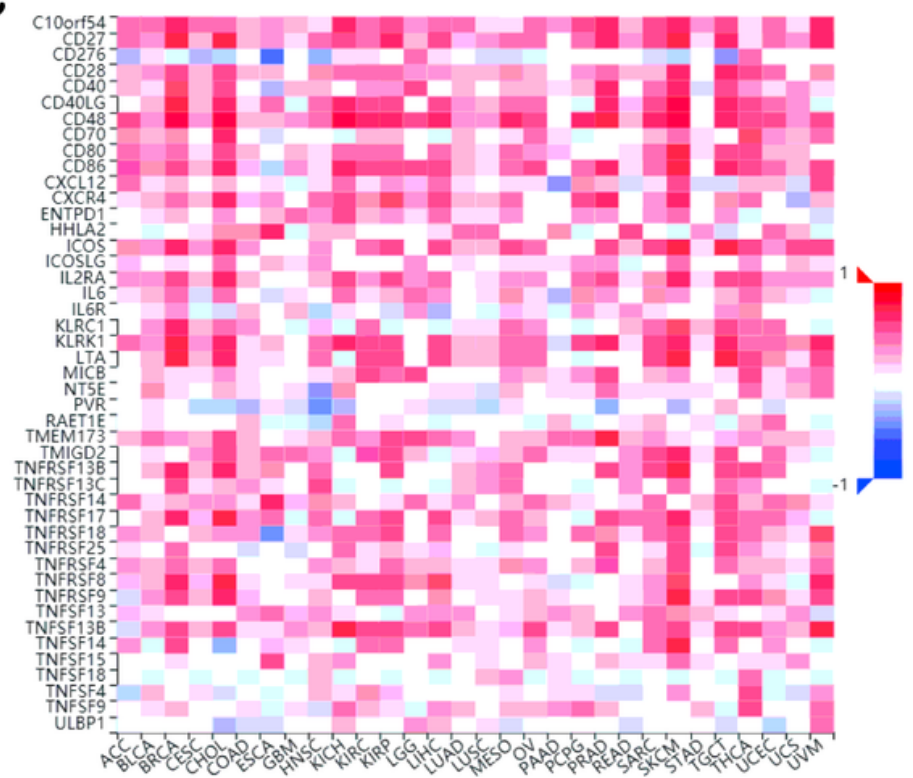

B

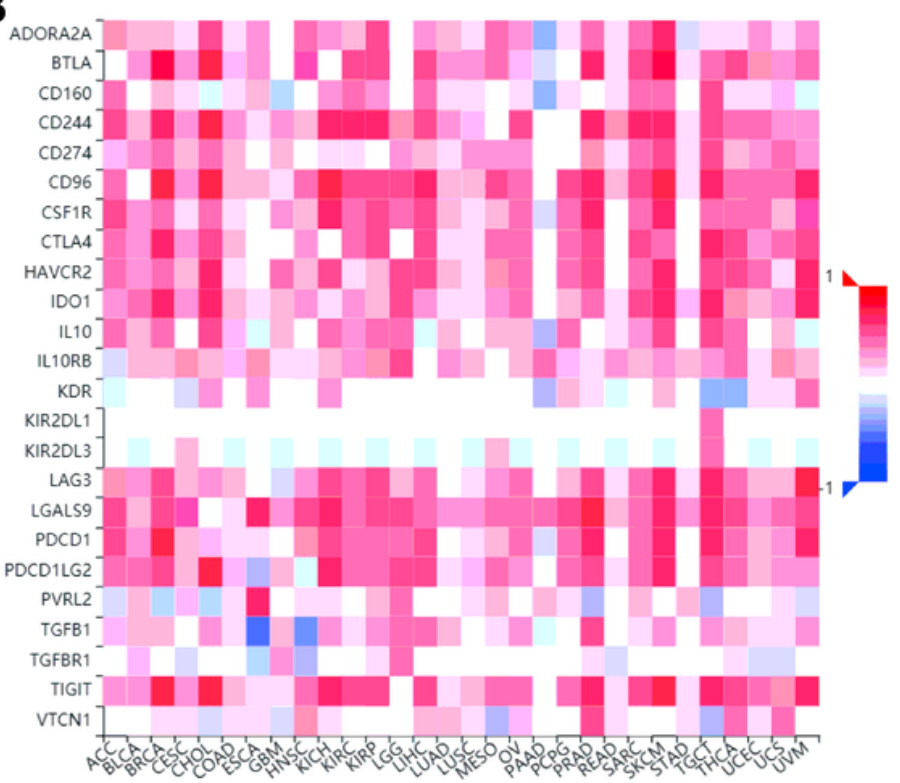

D

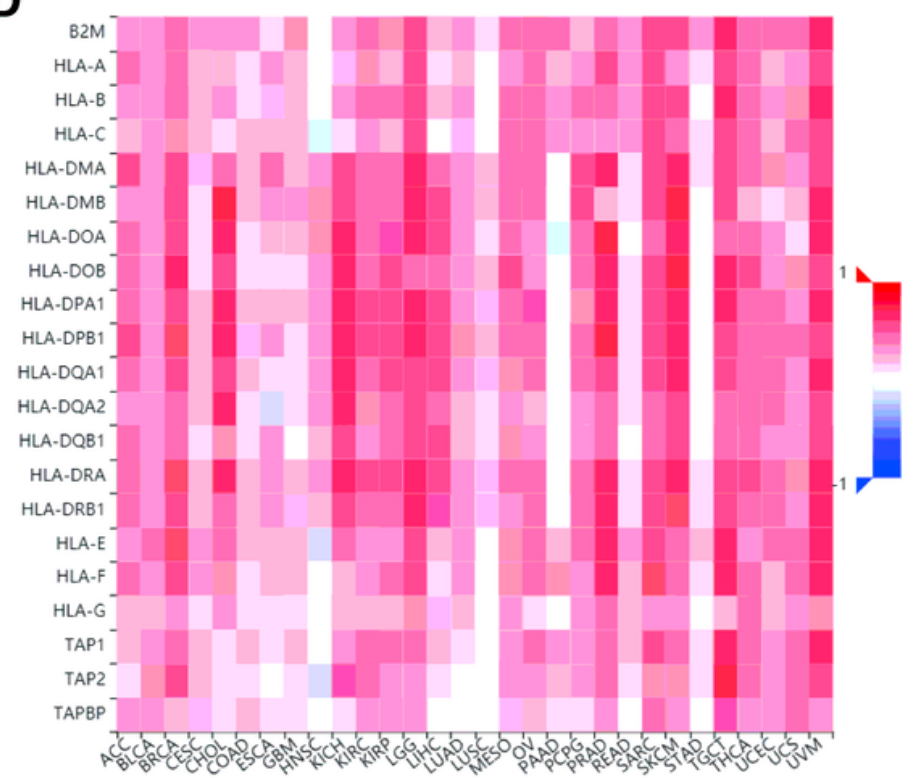

Figure 4

Spearman correlation between PLAC8 and lymphocytes as well as immunomodulators (TISIDB). (A) Correlation of TILs abundance with PLAC8 level. (B) Association of immuno-inhibitors abundance with PLAC8 level. (C) Correlation of immunostimulators abundance with PLAC8 level. (D) Relationship of MHC molecule abundance with PLAC8 level. Blue and red cells are suggestive of negative and positive correlations, respectively. There is a direct correlation between color intensity and correlation strength. 
A

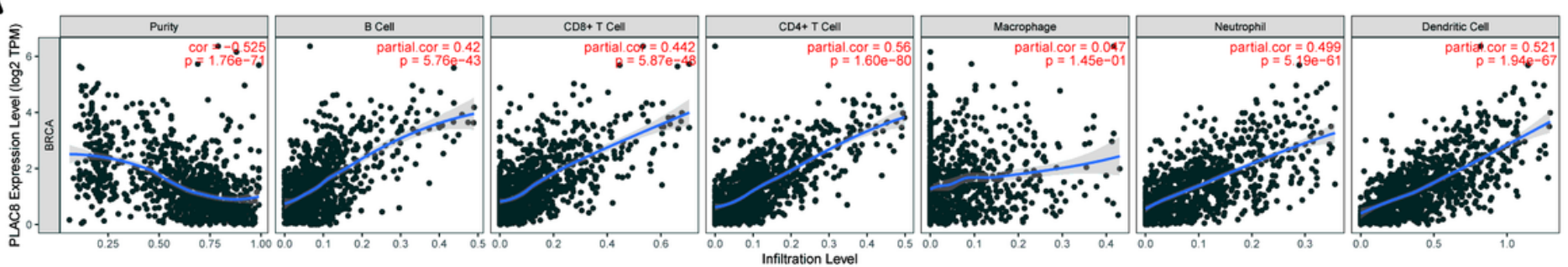

B

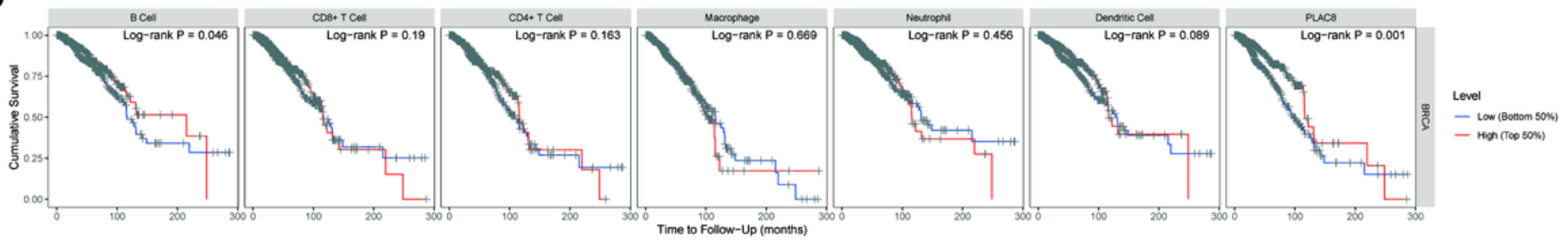

C

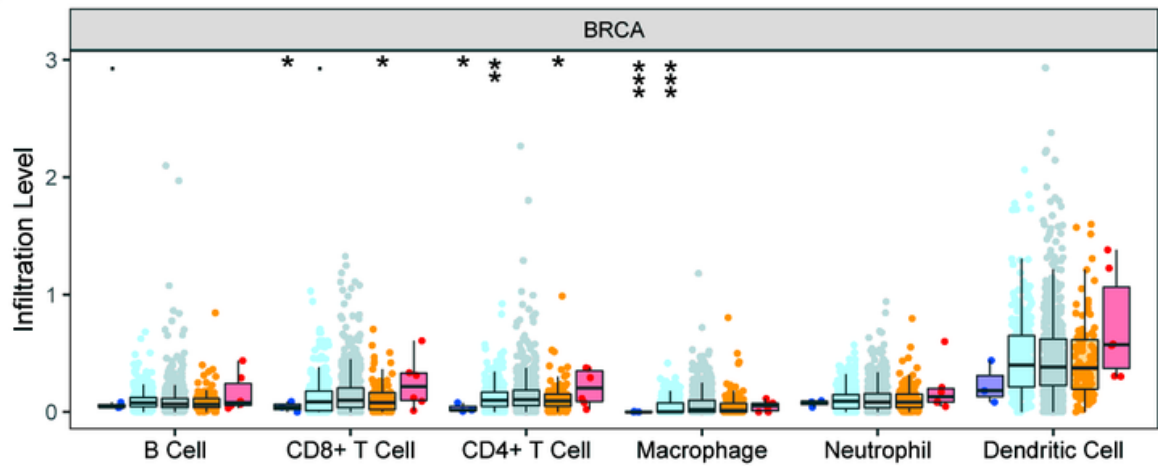

Copy Number

审 Deep Deletion

Arm-level Deletion

由 Diploid/Normal

审 Arm-level Gain

审 High Amplication

Figure 5

Association between PLAC8anddegrees of immune infiltration within BRCA. (A) Relationship of PLAC8 level with immune infiltration of tumor purity, neutrophils, B cells, CD8+ T cells, macrophages, CD4+ T cells, and DCs. (B) KM plots of immune infiltration and PLAC8 expression in BRCA. (C) Tumor-infiltration degrees compared with a variety of SCNAs to examine PLAC8 level within BRCA. The definition of SCNAs was according to GISTIC 2.0 (described in Method Section). P-value Significant Codes: $0 \leq \star \star \star<0.001 \leq$ $* *<0.01 \leq *<0.05 \leq$. $<0.1$ 
A

BRCA:: PLAC8_exp

$\mathrm{Pv}=3.54 \mathrm{e}-4 \overline{9}$

n=C1 369,C2 390,C3 191,C4 92,C6 40

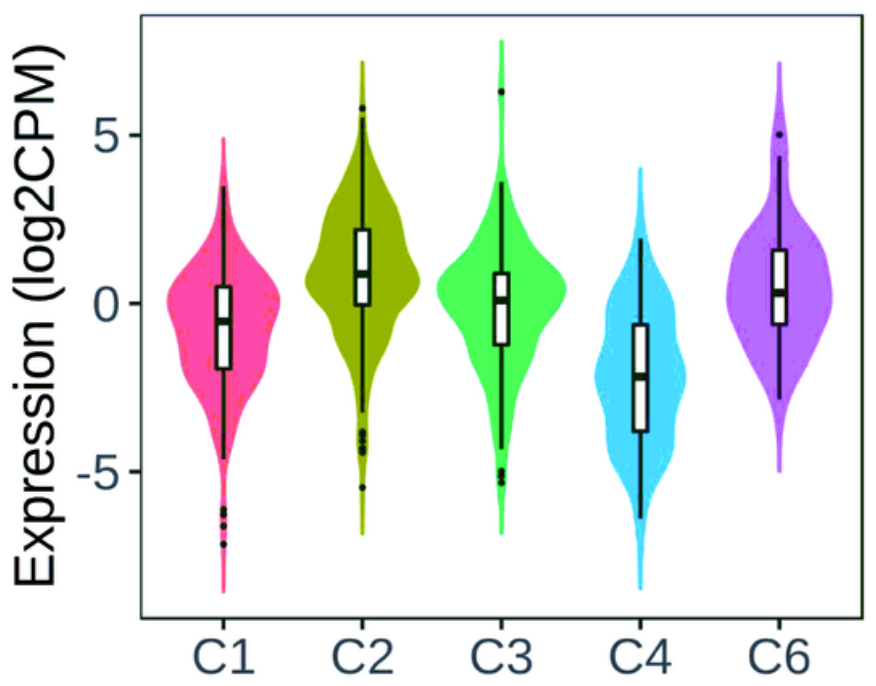

C1 (wound healing); C2 (IFN-gamma dominant); C3 (inflammatory); C4 (lymphocyte depleted);

C5 (immunologically quiet); C6 (TGF-b dominant)

\section{B}
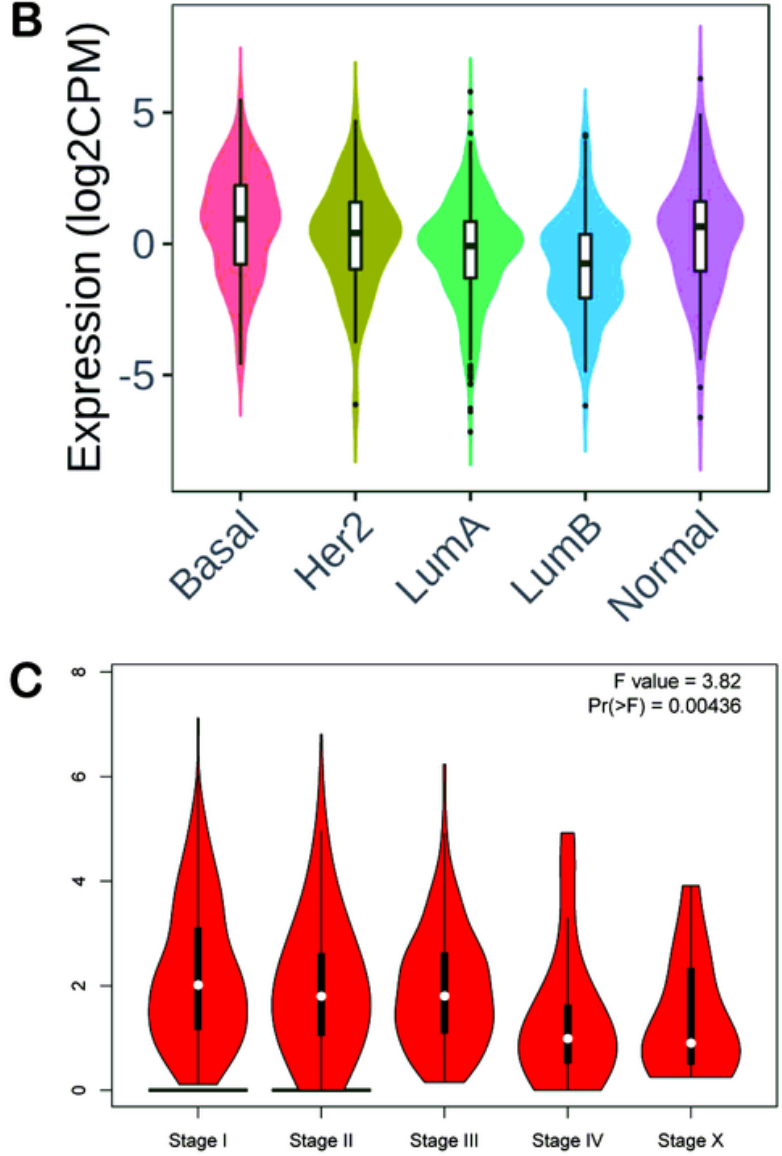

CA:: PLAC8 exp

$\mathrm{PV}=4.77 \mathrm{e}-1 \overline{6}$

$\mathrm{n}=$ Basal 172 ,

Her2 73,

LumA 508,

LumB 191,

Normal 137

D

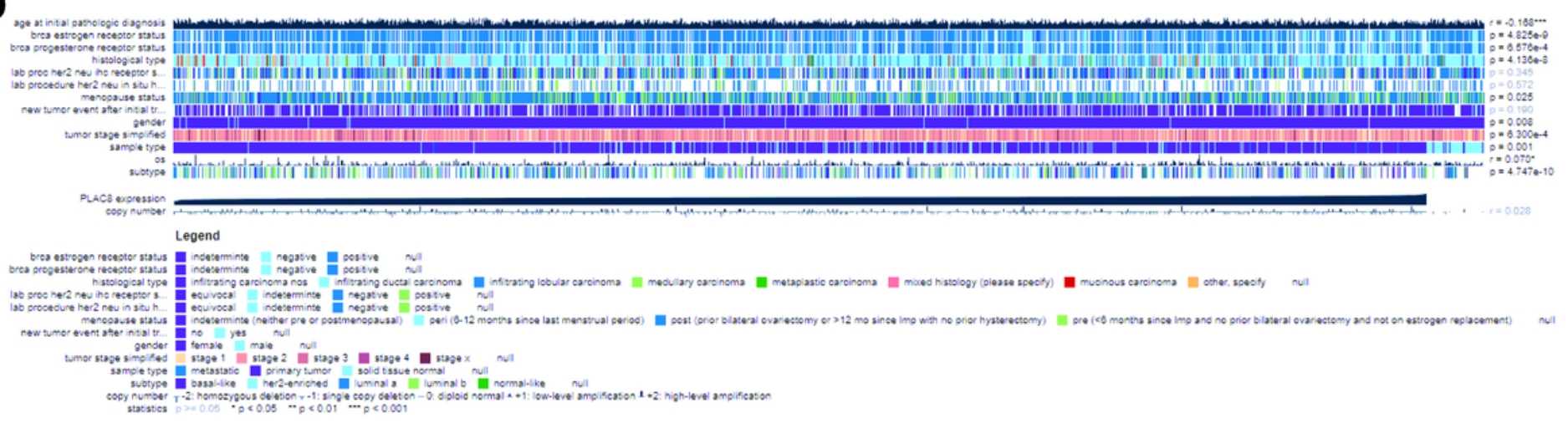

Figure 6

PLAC8 expression level in BRCA.PLAC8 expression in diverse (A) immune subtypes and (B) molecular subtypes of BRCA based on the TISIDB database. (C) PLAC8 expression at various stages in BRCA based on the GEPIA2 database. PLAC8 gene expression was normalized by log counts per million mapped reads $(\log 2 C P M)$ in $(A, B)$ and $\log 2(T P M+1)$ in $(C)$. (D) PLAC8 mRNA expression is correlated with histological type and sample type 

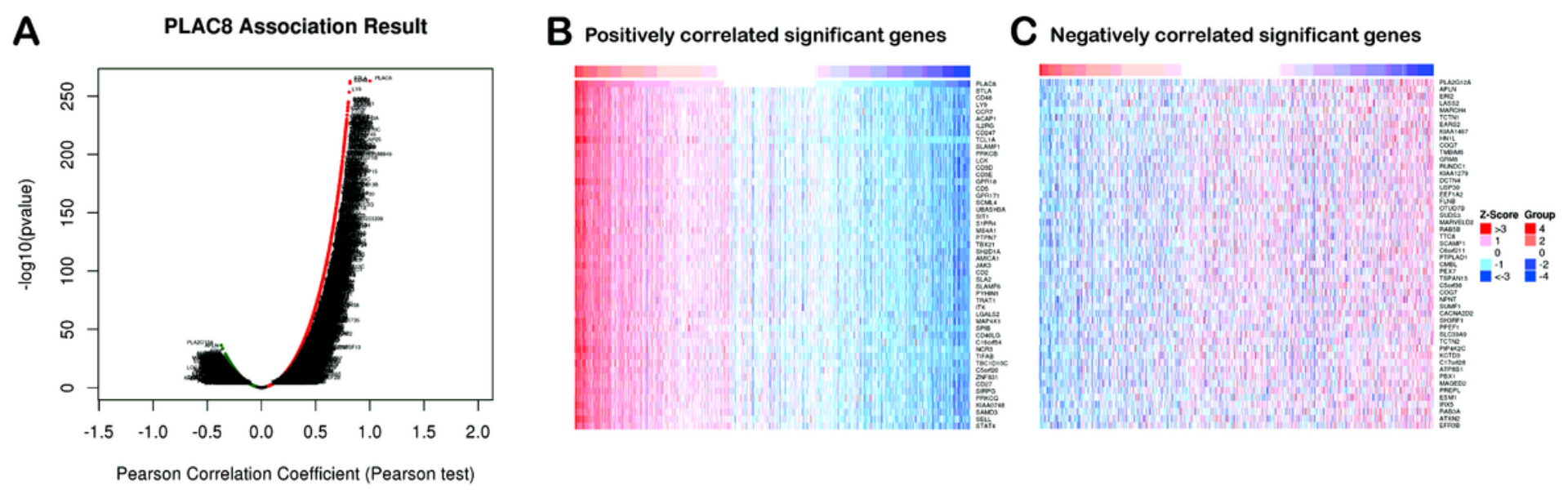

D

Biological process

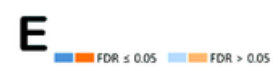

KEGG
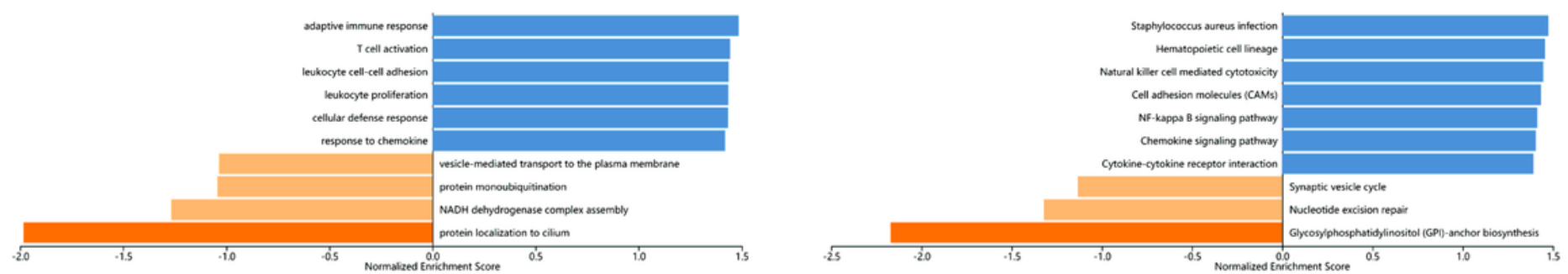

Figure 7

PLAC8 co-expression genes within BRCA (LinkedOmics). (A)Closely related genes of PLAC8 within BRCA identified by Pearson's test. Green and red dots indicated genes significantly negatively and positively associated with PLAC8, separately. (B, C) Heatmaps presenting the 50 most significantly negative and positive related genes of PLAC8within BRCA. (D, E)Markedly associated GO: BP annotations as well as KEGG pathways for PLAC8 within BRCA.

\section{Supplementary Files}

This is a list of supplementary files associated with this preprint. Click to download.

- FigureS1.tif

- Figures21.tif

- Figures22.tif

- Figures23.tif

- Figures24.tif

- Figures25.tif

- Tables1.docx 